\title{
Who is the "She" in the Pandemic "She-Cession"? Variation in COVID-19 Labor Market Outcomes by Gender and Family Status
}

\author{
Andrew Taeho Kim ${ }^{1}$ (D) Matt Erickson ${ }^{1} \cdot$ Yurong Zhang ${ }^{1} \cdot$ ChangHwan Kim $^{1}$
}

Received: 3 June 2021 / Accepted: 7 December 2021 / Published online: 29 January 2022

(c) The Author(s), under exclusive licence to Springer Nature B.V. 2021

\begin{abstract}
The sharp decline in employment after the COVID-19 lockdown was not uniformly felt across demographic groups. Utilizing the 2017 to 2020 monthly Current Population Survey and using a difference-in-difference design, we investigate the varying impacts of COVID-19 on at-work status among the prime-working-age population, accounting for typical seasonal fluctuations in employment. The target population is grouped by gender, marital status, parenthood, and level of education. Our results uncover complex variations by gender, marital status, and children's age. Contrary to popular belief, married women without school-aged children did not experience a relative decline in employment compared to married fathers. A majority of disadvantages in employment that married women experienced are accounted for by controlling for typical seasonal fluctuations. The women whose employment was most distinctively adversely affected by COVID-19 during 2020 were less-educated never-married childless women and never-married mothers. Less-educated men who were not currently married also experienced a disadvantage in employment relative to equally educated married fathers. These findings imply that, during the pandemic recession, marriage offered a form of within-family insurance that we call the "added caregiver effect." The further implications of these findings are discussed.
\end{abstract}

Keywords COVID-19 · Employment · Gender · Marital status · Parenthood

Andrew Taeho Kim

andrew_taeho@ku.edu

Matt Erickson

matt.erickson@ku.edu

Yurong Zhang

yurongzhang@ku.edu

ChangHwan Kim

chkim@ku.edu

1 Department of Sociology, University of Kansas, Lawrence, USA 


\section{Introduction}

As state and local governments instituted lockdowns to restrain the spread of COVID-19 in the spring of 2020, a pandemic-imposed recession began. The employment-to-population ratio in the U.S. plummeted from $59.9 \%$ in March to $51.3 \%$ in April, an 8.6-percentage-point drop. ${ }^{1}$ As of December, the employment-topopulation ratio $(57.4 \%)$ had not recovered to the pre-lockdown level. However, the decline in employment was not felt uniformly across demographic groups. Unlike in previous recessions, during which men tended to be more likely to lose their jobs than women (Goodman et al., 1993; Hoynes et al., 2012), more women than men lost jobs during the pandemic recession (Alon et al., 2020b; Landivar et al., 2020). Because of this, some news media outlets have labeled the 2020 recession a "Shecession", citing academic papers (Alon et al. 2020a, 2020b).

Researchers have worried that women's unemployment after the pandemic might further stall progress toward gender equality in employment or even reverse it (Alon et al., 2020a; Petts et al., 2021). The unique nature of the 2020 pandemic recession and its implications for future work arrangements, however, requires refined assessments of which groups are most negatively affected. Physical distancing and restrictions on opening hours affected service industries in which women are more concentrated than men (Cajner et al., 2020; Montenovo et al., 2020). Women's employment appeared to be slower to recover after April, the lockdown month, than men's (Alon et al., 2020b). However, women are also more likely to work in education-related occupations and industries that are sensitive to seasonal fluctuation (Raley et al., 2006). A failure to take into account these seasonal variations could lead to an overestimation of recession-related women's unemployment during the 2020 summer months.

The lockdown and remote working bring in a whole new set of policy-related issues such as childcare (Petts et al., 2021; Sevilla \& Smith, 2021), home schooling (Averett, 2021; Petts et al., 2021), out-of-school programs (Fornaro et al., 2021), sick leave (Jelliffe et al., 2021), and unemployment insurance (Ganong et al., 2020). The continuation of employment by teleworking became tightly entangled with the burden of childcare (Barkowski et al., 2020). A new burden of home schooling for parents because of school closures (Averett, 2021; Petts et al., 2021) was unevenly distributed between genders. However, the adverse impact of such conflict may not have been constant across all mothers. A survey reported that partnered parents' divisions of housework and childcare became more equal after the pandemic began (Carlson et al., 2020). This implies that, during the pandemic recession, marriage may have shielded women from voluntary unemployment due to the burden of childcare.

\footnotetext{
1 U.S. Bureau of Labor Statistics' Employment-population ratio: https://www.bls.gov/charts/emplo yment-situation/employment-population-ratio.htm Accessed on February 20, 2021.

${ }^{2}$ E.g., New York Times on May 9, 2020: https://www.nytimes.com/2020/05/09/us/unemployment-coron avirus-women.html; Bloomberg on December 30, 2020: https://www.bloomberg.com/opinion/articles/ 2020-12-30/covid-she-cession-the-pandemic-doesn-t-have-to-hurt-women-s-jobs-most.
} 
The shielding effect of marriage may also have varied across levels of education. The tasks of many highly educated workers can be done remotely, while those of less-educated workers tend to require physical contact and in-person presence (Montenovo et al., 2020). Highly educated workers tend to have jobs with paid sick leave, while less-educated workers who became victims of the pandemic at a higher rate typically lack this benefit (Jelliffe et al., 2021). The combination of the increased burden of child care at home and the continuing requirement of in-person contact at work could potentially have nullified the shielding effect of marriage for less-educated mothers. Given that variation in employment outcomes across demographic groups during the pandemic was larger among the less educated than among the highly educated (Kim et al., 2021), a failure to consider possible differentiated outcomes across levels of education among working mothers risks oversimplifying the nature of the pandemic recession and hindering policy responses.

In this study, we investigate variation across demographic groups in the impact of COVID-19 on at-work status. We aim to understand the peculiarity of the COVID19 related employment crisis by identifying which refined groups were the most adversely affected. To this end, we classify the prime-working-age population into fifteen groups-seven for men and eight for women-depending on gender, marital status, and parenthood. We further compare outcomes among these groups across levels of education. To account for typical seasonal fluctuations and pandemicrelated employment declines common to all groups, we use a difference-in-difference design, utilizing data from each monthly current population survey (CPS) sample from 2017 to 2020 . Our results demonstrate that the detrimental effects of COVID-19 on employment were much too complex for the simple "she-cession" label. A majority of disadvantages in employment that married women experienced are accounted for by controlling for typical seasonal fluctuations. The women whose employment was most distinctively adversely affected by COVID-19 during 2020 were less-educated never-married childless women and never-married mothers. These findings imply that marriage has offered a form of within-family insurance during the pandemic recession that we call the "added caregiver effect." Given that teleworking is likely to stay in the foreseeable future, this study contributes to the literature not only by uncovering which groups were more negatively affected by the pandemic recession but also by shedding new light on the role of family in employment, which will help with proper policy development in the era of remote working.

\section{Literature Review}

\section{Two Types of Economic Crises and Gender in Previous Literature}

The economic impact of a crisis on men and women's labor-market outcomes depends on the nature of the crisis. In general, men and women are not evenly distributed across occupations and industries, so they experience distinct economic circumstances when social events hit different economic segments. Typical economic recessions in the United States tend to lead to greater job losses for men than for women (Redbird \& Grusky, 2016). When banks stopped investing during the Great 
Recession, the male-dominated industries of manufacturing and construction were among those hit hardest, while the female-dominated education and health services sector suffered significantly less or even gained jobs (Borbely, 2011; Dunne \& Fee, 2010; Goodman \& Mance, 2011; Hout et al., 2011). Although men were hit harder by job loss than women during the Great Recession, women's employment recovered more slowly following the recession than men's did, largely because of large job cuts in the disproportionately female public sector during the post-recession period (Hartmann et al., 2014; Laird, 2017).

In the case of natural disasters such as hurricanes, female-dominated industries have typically been harder-hit (Fothergill, 1998; Morrow, 1999; Vigdor, 2008; Willinger \& Knight, 2012). In addition, when disasters create an additional caregiving burden within families, that burden is likely to fall on women (Peek \& Fothergill, 2008; Morrow \& Enarson, 1996). Because lower-income women are more likely to rely on extended-family networks for caregiving, these women face a more intense increase in caregiving demands when disasters make these networks inaccessible (Peek \& Fothergill, 2008).

In labor-market terms, the COVID-19 pandemic shares qualities with both natural disasters and economic recessions, without fitting neatly into either category. A typical recession, by definition, consists of a prolonged period during which the national economy experiences no growth (Hout et al., 2011). In contrast with the slow burn of a typical recession, however, the effect of COVID-19 was more like an explosion: Because of the lockdowns imposed early in the pandemic, economic activities and employment plunged essentially overnight. Additionally, the pandemic downturn was set apart from previous recessions in that the lockdown necessitated the disruption of many childcare and education arrangements, including the highly unusual closure of public schools that in some areas stretched on for many months. The immediate onset of the economic downturn and the sudden care burden borne by families were more typical of a natural disaster than a usual recession. Because of this, we would expect some differences in the labor-market effects of the pandemic recession, compared with a typical recession.

During a regular recession, a spouse or partner can serve as within-family insurance by stepping into the labor market in the event of a layoff, sickness of family members, or increased childcare. This so-called "added worker effect" was widely observed during previous economic recessions as women entered the labor force to maintain their families' income when their partners lost employment (Lundberg, 1985; Birinci, 2019; Pruitt \& Turner, 2020; Blundell et al., 2016; Sahin et al., 2010). During the pandemic recession, however, we might expect important differences in the way such within-family insurance might function. One possibility is that families with children would not benefit from such insurance due to the increased childcare load. Individuals who may otherwise have been able to increase their labor supply to compensate for a spouse's layoff might have had their time and energy occupied by childcare, making it impossible for them to increase their work hours or take a new job (Alon et al., 2020b). However, another possibility is that within-family insurance did play a role during this pandemic because "stay-at-home" work arrangements enabled some partnered parents to deal with the sudden childcare need, thus, preventing the other partner from exiting paid work, or facilitating the other partner's 
employment opportunities. For single parents, on the other hand, the entirety of this burden fell on only one individual, unless other family members or informal caregivers were available. During the pandemic recession, spouses and partners may have functioned as a shock absorber for parents, providing some degree of protection from the shock of the increased care burden, rather than functioning as labor-market insurance in the event of a job loss.

Further, partners may have functioned as pandemic shock absorbers in other ways, including for individuals without children. The wide-sweeping response to the pandemic altered many people's daily lives in ways beyond just work and childcare. Lockdowns also forced the closure of restaurants, cleaning businesses, and other services used to outsource labor that would otherwise be performed in the home. At the same time, lockdowns and distancing guidelines radically transformed many people's social lives, limiting or even eliminating in-person social contact with people outside one's own household. These changes affected individuals without children just as they affected parents, and a spouse or partner might have provided childless individuals emotional support and daily care that made the seismic effect of the pandemic response more endurable. Research on the psychological effects of marriage suggests it generally has a positive effect on mental well-being, including by providing a source of social and financial support, as well as by conferring emotional benefits such as self-efficacy (Waite, 1995; Williams et al., 2010). The social support provided by a spouse or partner can have a stress-buffering effect for married or partnered individuals, regardless of whether they have children (Carlson \& Kail, 2018; Cohen \& Wills, 1985). Because of this, married or partnered individuals may have been able to withstand the stress of the pandemic with less negative effect on their well-being relative to single individuals.

However, the stress-buffering benefits of marriage may not be uniform across socioeconomic strata. Carlson and Kail (2018) found that marriage provided better protection against depressive symptoms for lower-SES individuals than it did for higher-SES individuals. This difference was mediated in part by social support from friends and family: Higher-SES individuals tended to report higher levels of social support regardless of whether they were married, whereas lower-SES individuals tended to report very low levels of social support if unmarried but enjoyed a boost of social support when married. For higher-SES individuals, the social support provided by marriage might effectively just take the place of social support previously provided by other friends and family, whereas for lower-SES individuals marriage (or partnership) might provide a unique source of social support (Carlson \& Kail, 2018; Sarkisian \& Gerstel, 2008). For all these reasons, spouses and partners may have functioned as within-family insurance providing some protection against the stress caused by the pandemic's changes to everyday life, regardless of one's parenthood status, and this protection may have been most valuable for lower-SES individuals. If the stress of the pandemic had differential effects on well-being across lines of parenthood status and SES, it may have had differential effects on labor-market participation across those lines, as well.

Given these potential differential effects of the pandemic, we propose that during the pandemic recession, spouses and partners may have functioned as withinfamily labor-market insurance in a way different than that previously identified in 
the economic literature: by serving as an added caregiver rather than as an added worker. This "added caregiver effect"-the presence of a spouse or partner to provide care in the form of parenting or in the form of social support for one's partner-may have left couples better equipped to maintain their labor force participation during the pandemic relative to unmarried or unpartnered individuals.

\section{Differential Labor-Market Effects of COVID-19 by Gender, Marital Status, Parenthood Status, and Education}

\section{Gender}

Previous recessions have resulted in heavier job losses for men. Research on the initial pandemic-related spike in unemployment in April 2020, however, indicates a sharp contrast with previous economic downturns, as more women lost jobs than men (Alon et al., 2020b; Landivar et al., 2020). This gender gap in employment remained stable through at least June, though researchers using different data sources arrived at slightly different estimates of the extent of the gap (Adams-Prassl et al., 2020; Cajner et al., 2020; Montenovo et al., 2020).

As with past economic downturns, a likely explanation for this gender disparity is variation in impacts by industry, combined with industrial gender segregation. However, because the 2020 downturn was precipitated by a pandemic, the most affected industries were different from those in a typical recession. Industries involving a great deal of face-to-face interaction have been hard-hit by job losses (Cajner et al., 2020; Montenovo et al., 2020). These service-oriented industries have disproportionately female workforces, unlike the male-dominated industries of construction and manufacturing that are typically most affected by recessions (Alon et al., 2020b). Industries in which high proportions of workers are able to work remotely, on the other hand, have been relatively sheltered from job losses (Adams-Prassl et al., 2020; Papanikolaou \& Schmidt, 2020). Men are more likely to work in occupations in which at least $50 \%$ of workers report being able to work remotely, though conclusions on gender differences in ability to telecommute may vary based on the threshold used to define an occupation as "telecommutable" (Alon et al., 2020a; Montenovo et al., 2020).

Gender differences in industrial distribution also intersect with month-to-month economic fluctuations. Such monthly variations are associated with natural events, such as weather, or institutional schedules, such as school calendars, holidays, and the timing of tax collection (Geremew \& Gourio, 2018). Construction has a strong seasonal component; the employment rate is very low during winter. Outside of construction, the end-of-the-year holiday season typically brings the peak of U.S. GDP, as well as the temporary expansion of jobs in retail sale (Barsky \& Miron, 1989; Miron, 1996). Another related industrial seasonality is the increase of manufacturing activities around October, in preparation for the holiday season (Barsky \& Miron, 1989; Miron, 1996). Tourism and hospitality have business spikes during summer and traditional holiday seasons (Kelliher, 1989). Among all these monthly fluctuations, schools closing during summer seems to have the greatest impact on 
women's employment because the majority of primary and secondary teachers are women (U.S. Department of Labor, 2017). Therefore, conclusions about the gendered effect of any major social crisis could be biased without accounting for the monthly variation of industries.

Given these previous findings, we test the following two hypotheses:

Hypothesis 1a Overall, during the pandemic months of 2020 (April-December), monthly employment outcomes were worse for women than for men.

Hypothesis 1b This between-gender difference in employment outcomes will no longer be significant after controlling for current or most recent industry and occupation.

\section{Parenthood Status}

Using different data sources, researchers have found that the mediating effect of industry does not explain all of the gender gap in employment declines early in the pandemic downturn (Cajner et al., 2020; Montenovo et al.,2020). A commonly proposed mechanism for this unexplained portion of the gender gap is the increased care burden for mothers during the pandemic, due to school closures and the loss of childcare arrangements (Collins et al., 2021; Petts et al., 2021). Given gendered cultural beliefs about responsibility for parenting (Blair-Loy, 2003; Stone, 2007), we would expect the resulting additional childcare burden to fall primarily on mothers. Several researchers have studied whether increased parenting burdens might have led to a reduction in mothers' labor supply during the pandemic. Collins et al. (2021) found that the gender gap in weekly work hours increased by between 1 and $2 \mathrm{~h}$ for employed married parents of children younger than 13 during the initial months of the pandemic. However, another study that adjusted for seasonal trends in previous years found no significant difference between parents of children under 13 and parents of older children in terms of employment, being at work, or work hours in the initial months of the pandemic (Barkowski et al., 2020).

Employment changes during the initial lockdown period in the U.S. were driven largely by layoffs and not by voluntary quits, so it is unlikely that childcare burdens explain a large portion of the initial drop in employment during spring 2020 (Dias et al., 2020). However, as the increased childcare burden for many parents stretched on for many months, it may have had an effect later in the pandemic, especially in the fall as schools in many parts of the country continued to operate virtually all or some of the time. The frustration some women may have felt at their partners' lack of childcare support may have led to increased strain over time (Calarco et al., 2020). Or, as happened during the Great Recession, a change in the gendered division of labor at home sparked by an external shock may have gradually faded over time as familiar gendered patterns returned (Berik \& Kongar, 2013). Shorter school days have been found to create a barrier for maternal employment (Graves, 2013; Berthelon et al., 2015; Ruppanner et al., 2019). For parents of school-aged children, school is the main source of child care (Capizzano et al., 2002; Laughlin, 2010). Tedeschi (2020) found an association between states' rates of school closures and 
distance learning and the work outcomes of mothers of school-aged children as the 2020-21 school year began.

An additional proposed explanation for inequality in the pandemic labor market by gender and parenthood status is a fatherhood premium in avoiding post-pandemic layoffs. The gendered cultural model of the male breadwinner may lead employers to favor fathers over other workers in employment decisions, including whom to lay off during downturns (Correll et al., 2007). Dias et al. (2020) found that fathers had the lowest likelihood of being laid off by April 2020, compared with mothers and men or women without children.

Given these proposed mechanisms, we test the following hypotheses:

Hypothesis 2a During the pandemic months of 2020 (April-December), seasonally adjusted employment outcomes were better for fathers than for mothers, women without children, or men without children.

Hypothesis 2b During the final four months of 2020 (September-December), coinciding with the beginning of the 2020-2021 school year, seasonally adjusted monthly employment outcomes were worse for mothers of school-aged children (6-17) than for other gender and parenthood status groups.

\section{Marital Status}

Other theory and findings suggest that the effects of increased parental burdens might not affect all mothers in the same way. Although parents did face an unprecedented childcare and educational burden, those parents who shifted to full-time teleworking spent more time at home and less time at external workplaces during the pandemic, giving them more flexibility to balance paid work and childcare than they may have had previously (Lyttelton et al., 2020). It may be that the increase in remote working during the pandemic led to increased childcare participation by men, as they spent more time at home than ever before (Carlson et al., 2020; Alon et al., 2020a). One survey found evidence that partnered parents' divisions of housework and childcare became more even after the pandemic began, though the gender gap widened among couples in which the father was the sole or primary earner (Carlson et al., 2020). Research on the gender division of labor among teleworking parents prior to the pandemic has found that teleworking may narrow the gender gap in time spent on childcare (Lyttelton et al., 2020).

To this point, much of the sociological research on the gendered effects of the pandemic lockdown and recession has focused on partnered or married parents (Collins et al., 2021; Petts et al., 2021; Carlson et al., 2020; Calarco et al., 2020; Landivar et al., 2020). However, if remote working has prompted men to assume a greater share of the childcare burden among partnered parents, this suggests that the largest increased childcare burden at the onset of COVID-19 fell on single mothers rather than partnered mothers. Compared with partnered mothers, single mothers likely lacked flexibility in adapting to the loss of childcare due to the pandemic (Alon et al., 2020a). To the extent that women's labor-market outcomes may have 
been affected by increased childcare demands due to the pandemic, that effect may have been strongest among single mothers relative to married or partnered mothers.

Hypothesis 3 During the pandemic months of 2020 (April-December), employment outcomes were worse for single mothers than for married mothers.

\section{Education}

Just as the pandemic, by its nature, has had a greater effect on female-dominated industries, it has also had a greater effect on industries predominantly employing less-educated workers. Occupational segregation by gender has been much more persistent over time among individuals without college degrees than among college graduates (England, 2010). Further, job quality and employment security can vary within the same occupation and industry. Across all age, gender, and racial groups, increases in unemployment early in the pandemic were greater among individuals without college degrees (Kim et al., 2021; Moen et al., 2020). Workers in sectors characterized by face-to-face contact disproportionately do not have college degrees; workers with college degrees, on the other hand, are more likely to work in telecommutable occupations (Montenovo et al., 2020). Thus, mothers without college degrees were probably more likely than those with college degrees to lose their job involuntarily due to the pandemic. In the event that less-educated mothers were not laid off, they likely had less flexibility in adapting to increased childcare burdens given their inability to do their job remotely (Montenovo et al., 2020). Additionally, the spouses of married women without college degrees are themselves likely not to have graduated from college (Schwartz \& Mare, 2005), and therefore, less likely to be working remotely during the pandemic and able to assume some of the increased childcare burden. Given all this, differences in labor-market outcomes across gender and family status may be starker among individuals without college degrees than among college-educated individuals.

Hypothesis 4 Disparities in employment outcomes across demographic groups were greater among individuals without college degrees than among college graduates.

\section{Methodology and Research Design}

\section{Data}

We use the monthly CPS from January to December 2017-2020 from the Integrated Public Use Microdata Series (IPUMS) (Flood et al., 2020). The sample is limited to the prime-working-age population, ages $25-54 .{ }^{3}$ We further limit our sample to those not in school and exclude individuals who are currently serving in the military.

\footnotetext{
${ }^{3}$ We assessed the same analyses using slightly different age ranges such as $25-49$ and $18-64$. Results did not differ significantly.
} 
Because of the rotating sample nature of CPS, one person can appear more than once in our cross-sectional sample, which can induce a downward bias in the estimation of standard errors. To address this issue, we use person weights and obtain robust, clustered standard errors using individual IDs in all analyses.

\section{Dependent Variables}

Our primary dependent variable is a dichotomous measure of being at work last week (1) or being not at work (0). "Not at work" includes individuals who had a job but were not at work, as well as those who were unemployed or not in the labor force. Those who were unemployed because of temporary layoffs due to the COVID-19 lockdown should be classified as unemployed. However, a substantial portion of such individuals were miscategorized as employed but not at work (U.S. Bureau of Labor Statistics, 2020). Unemployment rates among those in the labor force can be biased because of this misclassification. We focus on the probability of being at-work, or the employment-to-population ratio, because it is not affected by this COVID-19-related misclassification and, thus, is the most stable measure of employment. ${ }^{4}$

\section{Main Independent Variables: Disaggregated Groups by Gender, Marital Status, and Parenthood}

Based on gender, marital status, and parenthood status, we classify respondents into seven male groups and eight female groups: (1) married fathers with youngest children ages 18+; (2) married fathers with youngest children ages 6-17; (3) married fathers with youngest children ages $0-5$; (4) married men without children; (5) never-married men; (6) cohabiting men; (7) separated/widowed/divorced men; (8) married mothers with youngest children ages 18+; (9) married mothers with youngest children ages 6-17; (10) married mothers with youngest children ages 0-5; (11) married women without children; (12) never-married mothers; (13) never-married women without children; (14) cohabiting women; and (15) separated/widowed/ divorced women, setting (1) married fathers with youngest children ages $18+$ as the reference group. We separate never-married singles and separated/widowed/ divorced primarily because of their age differences. Among prime working-age individuals, women's labor force participation tends to decrease in their 30s and early 40s (Goldin \& Mitchell, 2017). Considering that the average age for never-married singles and separated/widowed/divorced are the mid-30s and mid-40s, respectively, putting those two groups in the same category could cloud the estimates. Married parents are classified according to the age of the youngest co-resident child, with married fathers and mothers each divided into three groups depending on whether

\footnotetext{
${ }^{4}$ We assessed the same sets of analyses using dichotomous indicators of being in the labor force or being employed. Our conclusion holds.
} 
their youngest child was of preschool age, school age, or an adult. ${ }^{5}$ We do not separate never-married fathers from never-married childless men because the sample size of the former group is too small. For the same reason, we divide cohabiting and separated/widowed/divorced only by gender, without accounting for parenthood. See Appendix Table 2 for descriptive statistics for the 15 groups.

\section{Analytic Strategy}

To explore the differentiated impact of COVID-19, we use a difference-in-difference design. First, we explore monthly changes in at-work status during 2020 compared to January of that year, which constitute the first difference. Next, we compare these monthly changes across fifteen groups (the second difference). We assess Eq. (1) for monthly data as follows:

$$
y=\sum_{m=\text { Feb. }}^{\text {Dec. }} \beta_{m} M_{m}+\sum_{g=2}^{15} \delta_{g} G_{g}+\sum_{m=\text { Feb. }}^{\text {Dec. }} \sum_{g=2}^{15} \gamma_{m, g}\left(M_{m} \times G_{g}\right)+\sum \pi X+\alpha+\varepsilon,
$$

where $M$ is a vector of month dummy variables that differentiate February through December from January. $\beta_{m}$ captures the proportion at work relative to January in month $m$ in a given year. $G$ is a vector of fourteen dummy variables that differentiate the sample by marital and parenthood status. Our coefficient of interest $\gamma_{m, g}$ is a difference-in-difference (DID) estimate treating the month as a treatment, showing the added disadvantage of group $g$ relative to married fathers with youngest children ages $18+$ in proportion at work vs. January in month $m$.

A problem of Eq. (1) is that the assumption of a common trend (Wing et al., 2018) may not hold across the fifteen groups. Women are less likely to be at work during the summer than men. Parenting school-age children will affect summer employment as well. The failure to account for variations in seasonal fluctuation could result in an overestimation of the relative reduction in at-work status among women. To address this concern, we cancel out the variation in seasonal fluctuation across groups by introducing an additional difference point, the difference between 2020 and the previous years. That is, we assess a difference-in-difference-in-difference model as shown in Eq. (2):

\footnotetext{
5 The results were almost identical when we changed the criteria to the presence of any school-aged children rather than using the age of the youngest child.
} 


$$
\begin{aligned}
y= & \sum_{m=\text { Feb. }}^{\text {Dec. }} \beta_{m} M_{m}+\eta C+\sum_{m=\text { Feb. }}^{\text {Dec. }} \delta_{m}\left(M_{m} \times C\right) \\
& +\sum_{g=2}^{15} \gamma_{g} G_{g}+\sum_{m=\text { Feb. }} \sum_{g=2}^{15} \omega_{m, g}\left(M_{m} \times G_{g}\right)+\sum_{g=2}^{15} \theta_{g}\left(C \times G_{g}\right), \\
& +\sum_{m=\text { Feb. }}^{\text {Dec. }} \sum_{g=2} \psi_{m, g}\left(M_{m} \times C \times G_{g}\right) \\
& +\sum \pi X+\alpha+\varepsilon
\end{aligned}
$$

where $C$ is a dummy indicator that differentiates between 2020 and the non-pandemic years of 2017-2019. Our main coefficient of interest is $\psi_{m, g}$, a seasonally adjusted DID estimate. It compares the effect of the year 2020 (i.e., the pandemic year) on changes in the dependent variable across months $(m)$ for group $g$ relative to married fathers with youngest children ages $18+$. Throughout the paper, we call $\gamma_{m, g}$ of Eq. (1) “DID in 2020” and $\psi_{m, g}$ of Eq. (2) 'Seasonally adjusted DID'.

\section{Control Variables}

All multivariable analyses control for age, age squared, levels of education, race, marital status, citizenship status, state fixed effects, metro status, and number of children in the household. Levels of education differentiate between less than high school, high school graduates, some college, bachelor's degree holders, and graduate degree holders. Race variables distinguish whites, blacks, Asians, Hispanics and other non-Hispanic origin. The citizenship status variable consists of categories of citizen, naturalized citizen, and non-citizen. State fixed effects control for state-level variations in the strength of economic lockdowns and other unobserved state-level heterogeneity. The metro indicator identifies whether the respondent is in a metro area or not. In models controlling for occupation and industry, we use nine categories of occupation and thirteen categories of industry. ${ }^{6}$ For those who are not currently employed, we apply their previous occupation and industry information.

\section{Empirical Results}

Before examining differences across detailed groups, let's explore overall changes in at-work status for men and women. The at-work rate in January 2020 was 85.5\% for men and $73.2 \%$ for women. In April, soon after the onset of lockdowns, the rates plummeted to $71.2 \%$ for men and $58.3 \%$ for women (see Appendix Table 2 for details). Figure 1A shows changes in the proportion at work relative to January in 2017-2019 and 2020 by gender. The changes are net of the control variables specified above. Both genders experienced a substantial drop in at-work rate in April 2020 and subsequent months (dotted gray line). The magnitude of

\footnotetext{
${ }^{6}$ When detailed 635-category occupation and 280-category industry are used instead of broad categories, the results are nearly identical with what we report here.
} 
A. Gendered monthly fluctuations

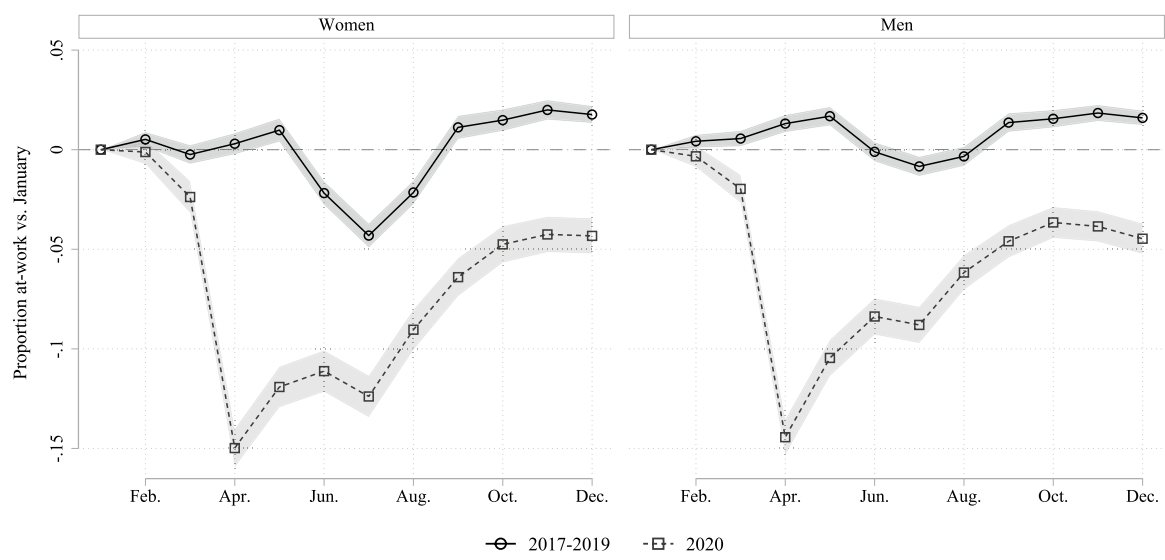

B. Women's disadvantage relative to men

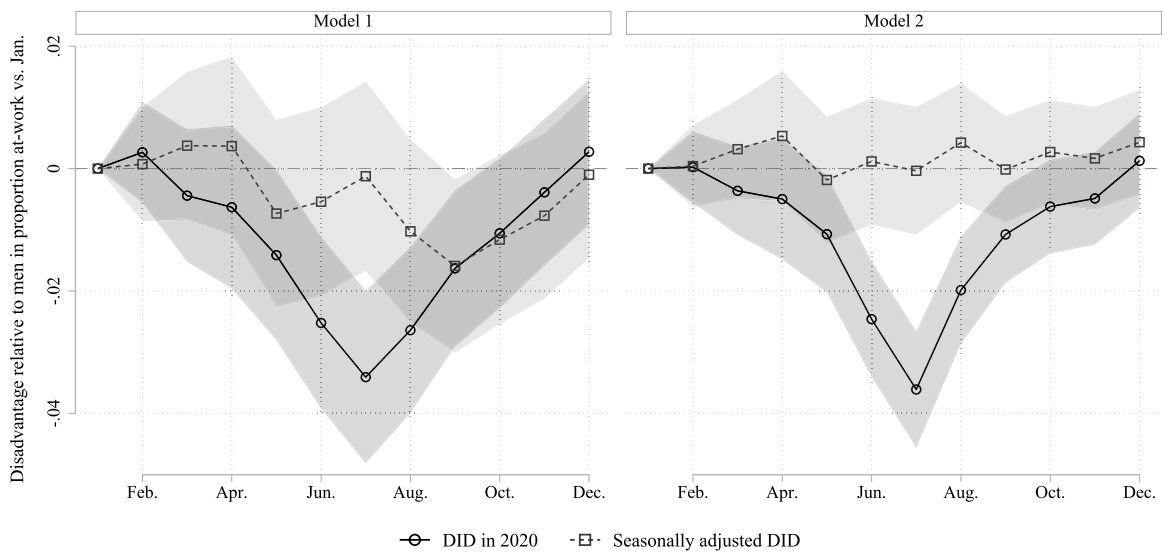

Fig. 1 Gender differences in proportion at work vs. January, 2017-2020. A shows the difference at-work rates from January. B shows $\gamma_{m, g}$ from equation (1) and $\psi_{m, g}$ from Eq. (2) in month $m . g$ is replaced with a dummy variable indicating women. Control variables include age, age squared, levels of education, race, citizenship status, state, metro status, number of children in the household and marital status. Model 2 of b controls for occupation and industry. Shaded area indicate $95 \%$ confidence intervals

the initial drop in the lockdown month of April is similar between genders. During the reopening period from May to August, however, men's at-work proportion seemed to recover at a faster pace than women's.

When we track the change in at-work rates in 2017-2019 (solid black line), distinct gendered monthly fluctuations in at-work status emerge. Women show a much larger drop in at-work status during the summer months relative to January (-0.022 in June, -0.043 in July, and -0.021 in August). While men show a drop in summer, the magnitude is not comparable. A failure to account for this 


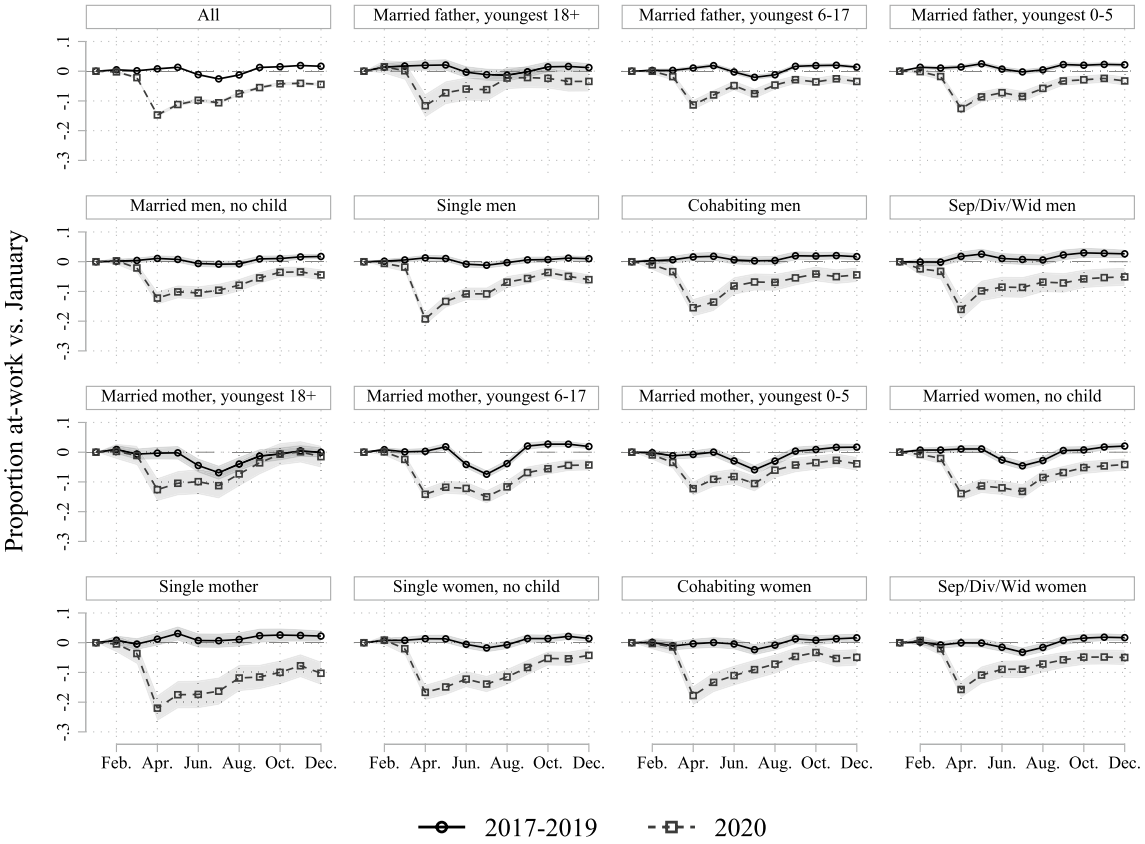

Fig. 2 Change in proportion at work compared to January, 2017-2020. Control variables include age, age squared, levels of education, race, citizenship status, state, metro status, number of children in the household and survey year for 2017-2019. Shaded area indicate 95\% confidence intervals

seasonal fluctuation could result in a misinterpretation of the pre-existing gender gap as the effect of the pandemic.

Indeed, Fig. 1B shows the importance of adjusting for seasonal fluctuations. Without the adjustment for seasonal fluctuation, DID in 2020 shows a larger gender gap during the summer months of 2020, reaching - 0.034 in July. When we adjust for seasonal fluctuations from years prior in Model 1, the gap is reduced to -0.001 and statistically insignificant. The statistically significant women's disadvantage in employment right after the lockdown is mostly attributable to seasonal fluctuations. When schools reopened in September, however, the seasonally adjusted gender gap emerged. Hypothesis 1a is only partially supported. Further, the additional female disadvantage specific to 2020 is fully accounted for by occupation and industry in Model 2, which supports Hypothesis 1b. The next question is whether these patterns vary across marital status and parenthood.

\section{Changes in At-Work Status: 2017-2019 vs. 2020}

Figure 2 shows the proportion at work relative to January in 2017-2019 and 2020 for fifteen demographic groups. For 2017-2019, we add controls for survey year on top of the other control variables. For men, regardless of marital and parenthood status, there was no distinct fluctuation across calendar months in 2017-2019. For 
women, seasonal fluctuation in at-work status differed by marital status and parenthood. Across groups, three distinct patterns emerge. First, before the pandemic, all groups of married women experienced a drop in the probability of being at work during the summer. Even married childless women experienced a drop in employment. Second, never-married and cohabiting women, regardless of motherhood, did not show noticeable seasonal fluctuation in employment in 2017-2019.

Third, never-married men and women suffered the most from the pandemicimposed recession. Never-married mothers' at-work status decreased by 22.0 percentage points in April 2020 compared to January. Surprisingly, never-married men experienced the second-largest drop (19.3 percentage points) after never-married mothers.

Another noteworthy point from Fig. 2 is that the month of the lowest at-work rate in 2020 was not necessarily April for married women. Their at-work rate in July was similar to that in April or even lower. Together, these results suggest the effect of COVID-19 varied across gender, marital and parenthood status.

\section{DID Estimates in At-Work Status}

Next, we examine the extent to which the effect of COVID-19 differed by gender, marital and parenthood status. First, we look at monthly changes relative to married fathers with youngest children ages 18+ in 2020 using DID estimates from Eq. (1), which controls for demographic covariates and education. Second, we adjust the DID estimates to account for monthly fluctuations observed in prior years (2017-2019), resulting in the Seasonally adjusted DID estimates from Eq. (2). Figure $3 \mathrm{~A}$ presents the result. The differences between the two estimates quantify the extent to which the failure to account for the seasonal fluctuation biases the relative (dis)advantage of a given group.

Out of the 14 groups that we compared to married fathers with youngest children ages $18+, 9$ groups experienced relative disadvantage in at least 1 month after adjusting for seasonal fluctuations: (1) married fathers with youngest children ages 0-5; (2) married men without children; (3) never-married men; (4) cohabiting men; (5) separated/divorced/widowed men; (6) married mothers with youngest children age 6-17; (7) married women without children; (8) never-married mothers; and (9) never-married women without children. Five groups did not experience statistically significant disadvantages in employment throughout the year 2020: (1) married fathers with youngest children age 6-17; (2) married mothers with youngest children age 18+; (3) married mothers with youngest children age 0-5; (4) cohabiting women; and (5) separated/divorced/widowed women. For disadvantaged groups, the timing and the magnitude of disadvantage vary.

Never-married mothers were the only group who experienced a substantial disadvantage for the entire year after the lockdown. For never-married and other not-married women, the seasonal adjustment did not alter estimates of their relative disadvantage. Beginning in April (- 0.090), never-married mothers continuously had the largest disadvantage in every month, statistically significant in every month except November, throughout the entire year. It should be emphasized that 
A. Without the Control of Occupation and Industry

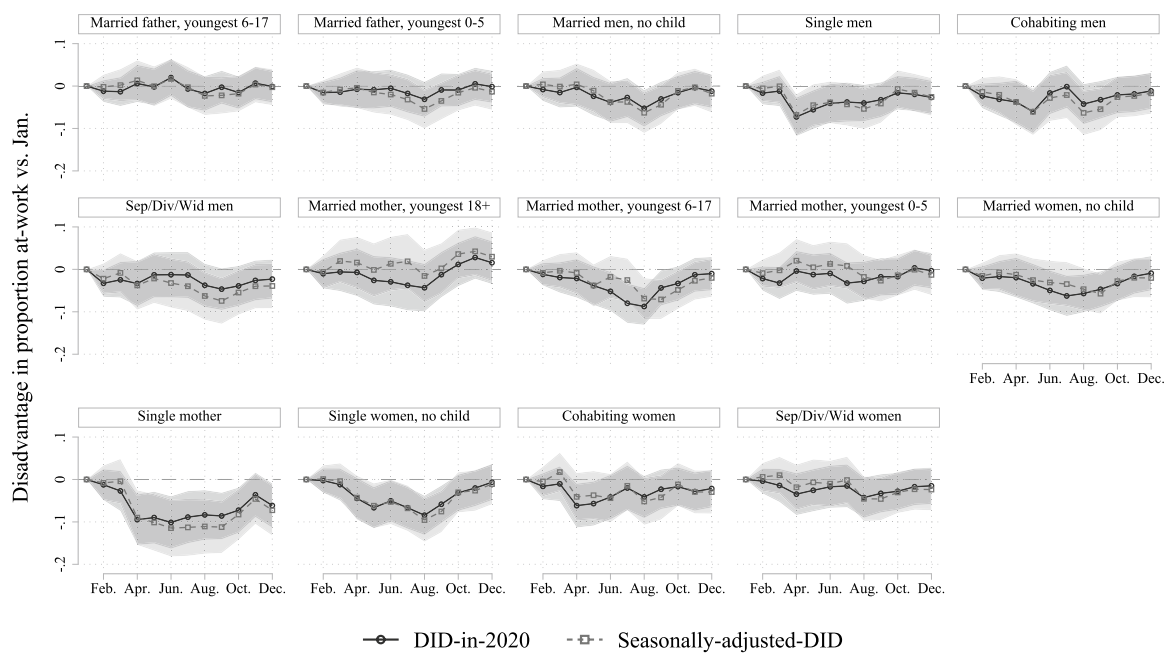

B. Seasonally-adjusted-DID with the Control of Occupation and Industry

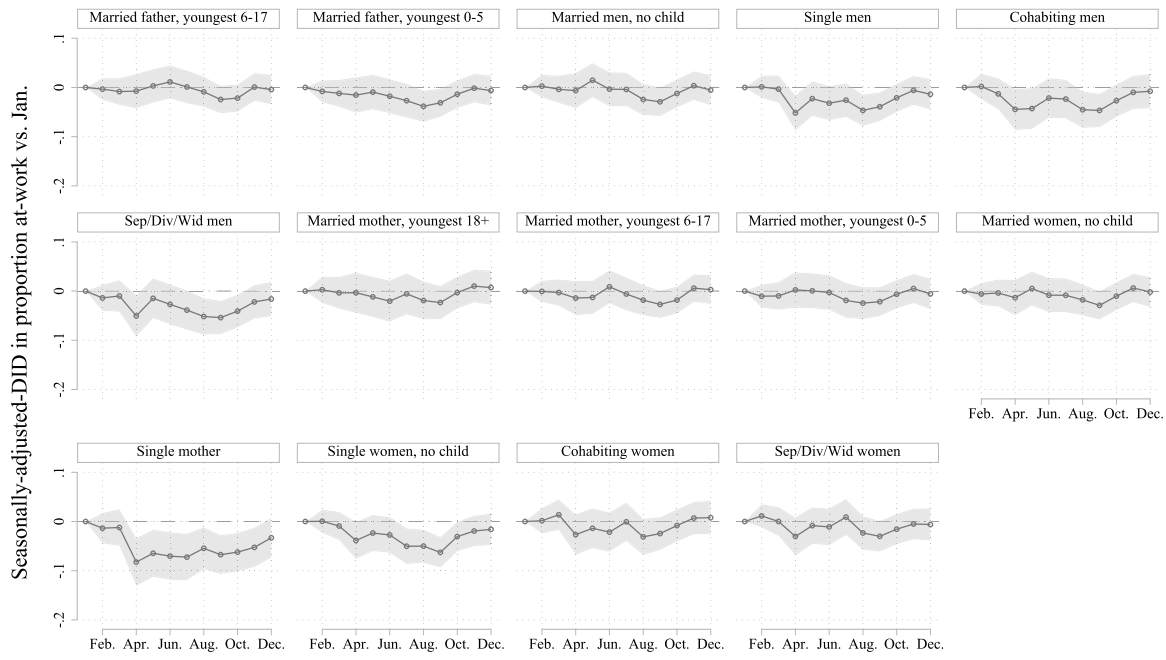

Fig. 3 Disadvantage relative to married fathers with youngest children ages $18+$ in proportion at work vs. January. Control variables include age, age squared, levels of education, race, citizenship status, state fixed effects, metro status, and number of children in the household. Shaded area indicate $95 \%$ confidence intervals based on robust standard errors

the disadvantages shown in Fig. 3A are added disadvantages on top of the drop in employment experienced by the reference group, married fathers with youngest children age $18+$. Childless never-married women were the second most negatively affected group by the lockdown. They experienced a notable disadvantage in atwork status from April to September. These findings support Hypothesis 3 strongly. 
Unlike for never-married women, the seasonal adjustment made noticeable changes in estimations for married women. Especially during the summer months, the magnitude of relative disadvantage for married women was reduced after seasonal adjustment. The reduction in relative disadvantage is particularly large for married mothers of school-aged children (youngest age 6-17), although the disadvantage for this group is still statistically significant. This result does not fully support Hypothesis 2a. The timing of the worst disadvantage for this group was not during the months right after the lockdown. Instead, it was during the school reopening months in fall 2020. Their seasonally adjusted-DID estimate compared to married fathers of school-aged children was -0.049 in September, which indicates that the at-work rate for married mothers of school-aged children declined by an additional 4.9 percentage points compared to married fathers with school-aged children even after factoring in seasonal fluctuations. These findings offer support for Hypothesis 2 b. Because school is likely the main source of childcare for these families (Capizzano et al., 2002; Laughlin, 2010), the partial school opening in fall 2020 seems to have imposed an extra burden on married mothers of school-aged children. In the case of married mothers of preschool-aged children and married mothers of adult children, no statistically significant disadvantage relative to married fathers is evident after seasonal adjustment. This implies that the relatively larger drop in at-work status for married women during summer 2020 was mostly attributable to typical gendered monthly fluctuations in at-work status across calendar months.

An interesting and unexpected finding from Fig. 3 is that not-currently married men and married men without children were also relatively disadvantaged compared to married fathers. During the months right after the lockdown, the relative disadvantages of never-married men were larger than those of any married female groups. Similar to married childless women, married childless men showed a mild disadvantage relative to married fathers. Cohabiting men and separated/divorced/windowed men experienced statistically significant negative impacts in some months. Their disadvantages look even larger (although statistically insignificantly different) compared to their female counterparts.

The complexity of the effects of COVID-19 by gender, marital status and parenthood could be related to the differences in occupational and industrial distributions across these groups. Gendered seasonal fluctuations are also germane to gendered occupational and industrial distributions (Raley et al., 2006). Industries such as eating and drinking places, retail trade, and services, in which women are concentrated, suffered the most in April right after the lockdown (See Appendix Figs. 7 and 8 for the changes in at-work status across months by industry and by occupation). At the same time, as in other recessions, employment in the male-dominated construction sector declined as much as that of retail trade. In terms of occupations, while lowskilled occupations were hit hard, high-skilled occupations such as business- and finance-related occupations and computer/engineering/science occupations showed hardly any changes between 2017-2019 and 2020.

Among all industries and occupations, education-related industries/occupations were the only sectors demonstrating a deep reduction in employment during the summer months routinely prior to 2020. Workers in education-related sectors reduced their labor supply substantially during the summer. The at-work rate 
A. Without the Control of Occupation and Industry

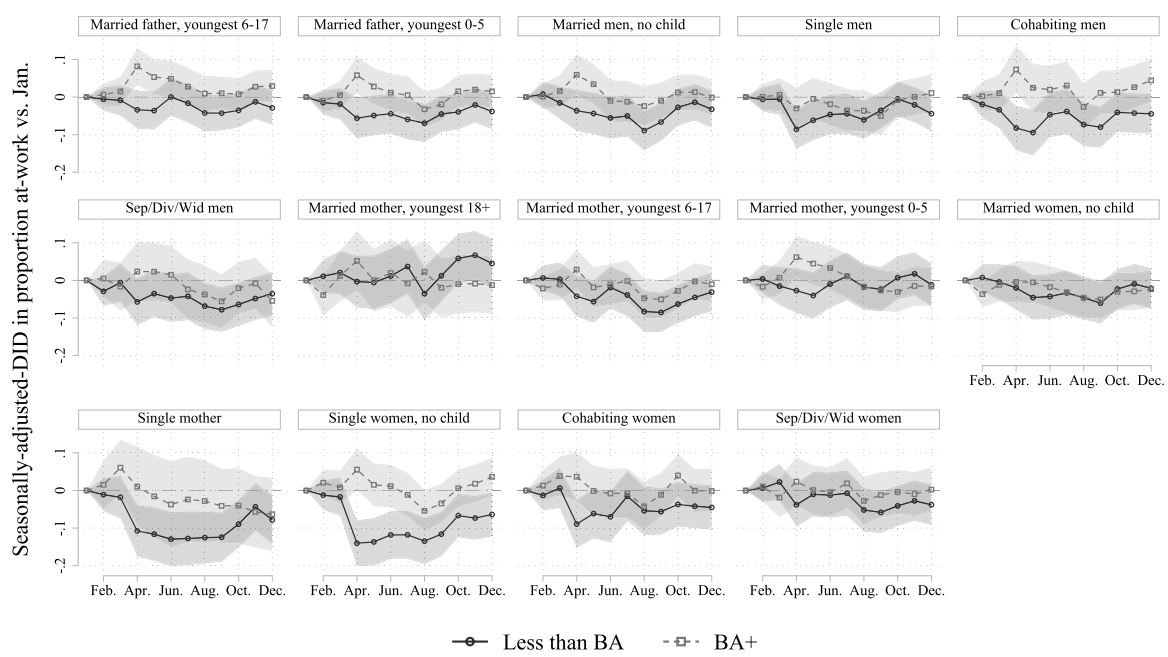

B. With the Control of Occupation and Industry
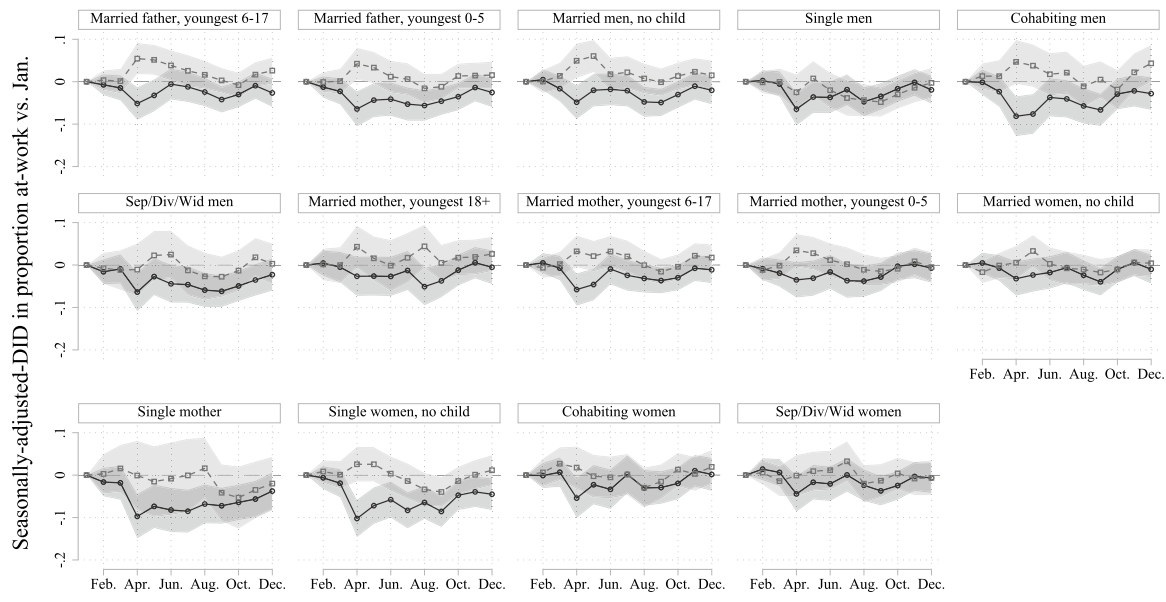

$\rightarrow$ Less than BA $-\because-\mathrm{BA}+$

Fig. 4 Seasonally adjusted disadvantage relative to married fathers with youngest child ages $18+$ in proportion at work vs. January by levels of education. Control variables include age, age squared, levels of education, race, citizenship status, state fixed effects, metro status, and number of children in the household. Shaded area indicate $95 \%$ confidence intervals

declined by $33.5 \%$ in July for the education service industry during 2017-2019. Relative to the other groups in our analysis, married mothers of school-aged children were the most concentrated in education sectors. Around one fifth of married mothers of school-aged children worked in education sectors, compared with only one twentieth of married fathers. In Fig. 3B, we examine whether industrial and 
occupational compositions could account for the differentiated impact of the lockdown across groups.

The relative disadvantages of all married women and of married childless men are fully explained away by industry and occupation. The reason why married mothers of school-aged children bore a larger negative shock is that they were more concentrated in industries and occupations that either fluctuate seasonally or were hit harder than other sectors during the pandemic recession.

Unlike that of married women, the disadvantages of all five not-married groupsnever-married men, cohabiting men, separated/divorced/widowed men, childless never-married women, and never-married mothers - remain statistically significant net of occupation and industry. This finding suggests that marriage operates as a buffer rather than an amplifier when it comes to pandemic-related job losses.

\section{Differences by Levels of Education}

To explore whether differentiated disadvantages across groups vary further depending on levels of education, we divide groups by whether they have a bachelor's degree (the highly educated) or not (the less-educated). Figure 4 shows the results. The contrast between the less educated and the highly educated is striking. Among those with Bachelor's degrees, no group is statistically more disadvantaged compared to married fathers with youngest children age 18+ either before or after the control of occupation and industry. Even never-married mothers did not seem to suffer from relative disadvantages when they were college educated, at least during the months right after the lockdown and before the school reopening in Fall. These results imply that among the college educated, gender, marital status, and parenthood were not associated with relative disadvantages in employment.

However, the likelihood of employment for the less educated does vary statistically significantly depending on gender, marital status, and parenthood. As shown in Fig. 4A, all less-educated groups, except married mothers of non-school-age children, experienced exacerbated disadvantage after the lockdown, although the period and the magnitude of the disadvantages varied across groups. The elevated disadvantages of never-married men, cohabiting men, separated/divorced/widowed men, never-married childless women, and never-married mothers evident in Fig. 3 were almost completely driven by disadvantages among the less-educated.

Less-educated childless never-married women and never-married mothers were substantially more likely to lose their employment after the lockdown. Interestingly, less-educated married fathers with young (age 0-5) children and married childless men also experienced an exacerbated drop in employment after the lockdown. Surprisingly, less-educated married mothers with young (age 0-5) children or adult children did not experience more negative drops in employment compared to married fathers with adult children. Overall, these findings support Hypothesis 4. Disparities in employment outcomes across groups were greater among the less educated than among the highly educated. 
Occupation and industry can explain only part of the relative disadvantages for the less educated. ${ }^{7}$ The exacerbated disadvantages for less-educated groups remain statistically significant in Fig. 4B. In particular, the disadvantages of less-educated never-married childless women and never-married mothers remain astonishingly high after the control of occupation and industry.

In sum, the groups that were the most severely disadvantaged for a prolonged period after the initial lockdown were less-educated never-married childless women and never-married mothers. Less-educated married mothers of school-aged children, less-educated married men without children, and less-educated not-currently married men also experienced relative disadvantages compared to similarly less-educated married fathers.

\section{Work Hours, Earnings, and Earnings Inequality}

Changes in labor-market outcomes affected by COVID-19 may have gone beyond employment status. In this section, we briefly examine changes in work hours, earnings, and earnings inequality among those who maintained at-work status after the lockdown. Figure 5 presents DID estimates for work hours and earnings, applying the same model specification we used in the analyses of at-work status. ${ }^{8}$

For both weekly work hours and weekly earnings, we find surprisingly null seasonally adjusted DID estimates for all groups. No group showed substantial or statistically significant disadvantages compared to married fathers in terms of work hours or earnings. Never-married women and mothers, the most negatively affected groups in terms of at-work status, did not experience more reduction in work hours and earnings than other groups. While there were distinct variations in the effect of COVID-19 by marital and parenthood status in terms of being at work, we find no evidence that work hours or earnings among those who stayed at work were affected differently by gender, marital status, or parenthood. We checked whether the results differed when the groups were further divided by education, finding no such outcomes. To check whether the pandemic recession affected part-time and full-time employment status differently across groups, we limit our sample to those who were employed and then estimate the changes in the likelihood of part-time employment, finding no variation across the 15 groups.

For an additional robustness check, we explore whether those who lost jobs during the pandemic recession were those who were employed part time before the pandemic. This analysis requires longitudinal data. Exploiting the rotation group of

\footnotetext{
7 Less-educated mothers with youngest children age $18+$ seem to have been advantaged in October and November before controlling for occupation and industry, but the advantages disappear with the controls of occupation and industry in Fig. 4. We checked whether distinct industrial or occupational distributions could account for their advantages, but did not find such evidence. This group seems to have been more likely than other groups to have been protected when they worked in government and health-related sectors, but such advantages were observed only in November. We suspect that the November advantage might be a short-term data fluctuation rather than a reflection of a systematic advantage.

${ }^{8}$ For weekly earnings, we limit our sample to respondents with positive earnings in the outgoing rotation group of the CPS.
} 
A. Weekly Work Hours

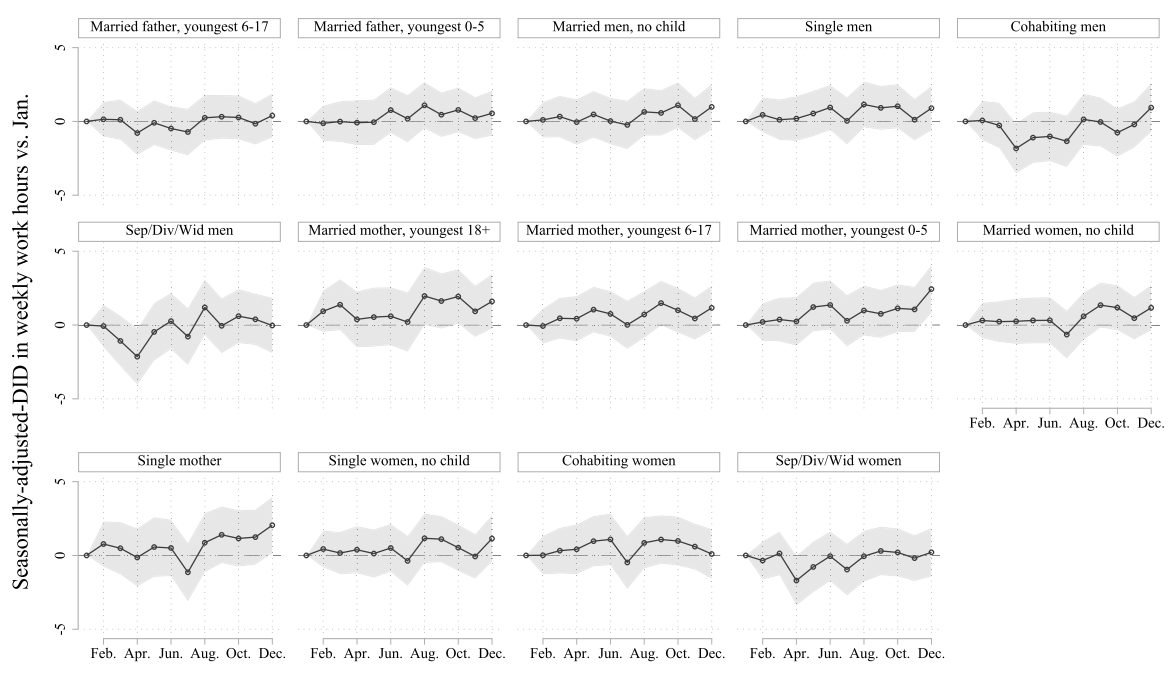

B. Weekly Earnings

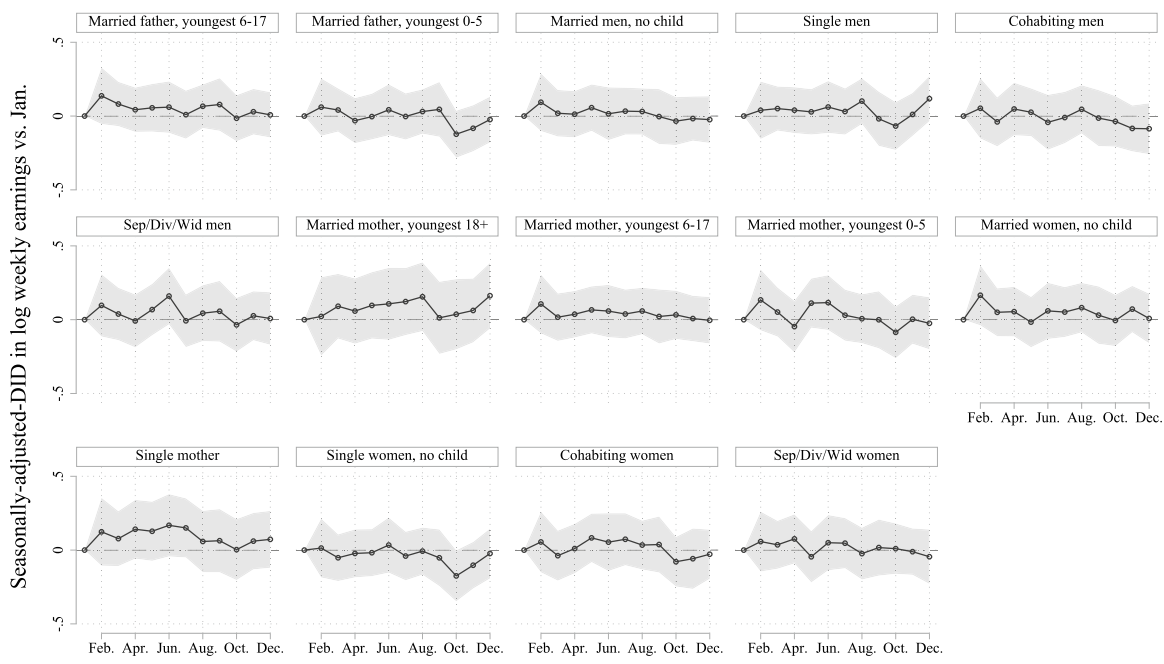

Fig. 5 Seasonally adjusted relative (dis)advantage in weekly work hours and weekly earnings compared to married fathers among employed. Note: Samples are limited to those employed in the month of survey. Control variables include age, age squared, levels of education, race, citizenship status, state fixed effects, metro status, and number of children in the household. Shaded area indicate $95 \%$ confidence intervals

the CPS, we construct a new mini-panel dataset where the same individuals appear in two adjacent years. The sample is limited to those who appeared in consecutive years in the same month. With these data, we investigated whether employment status measured before the pandemic could explain away the employment disadvantages among those without a BA, finding no such effect. 


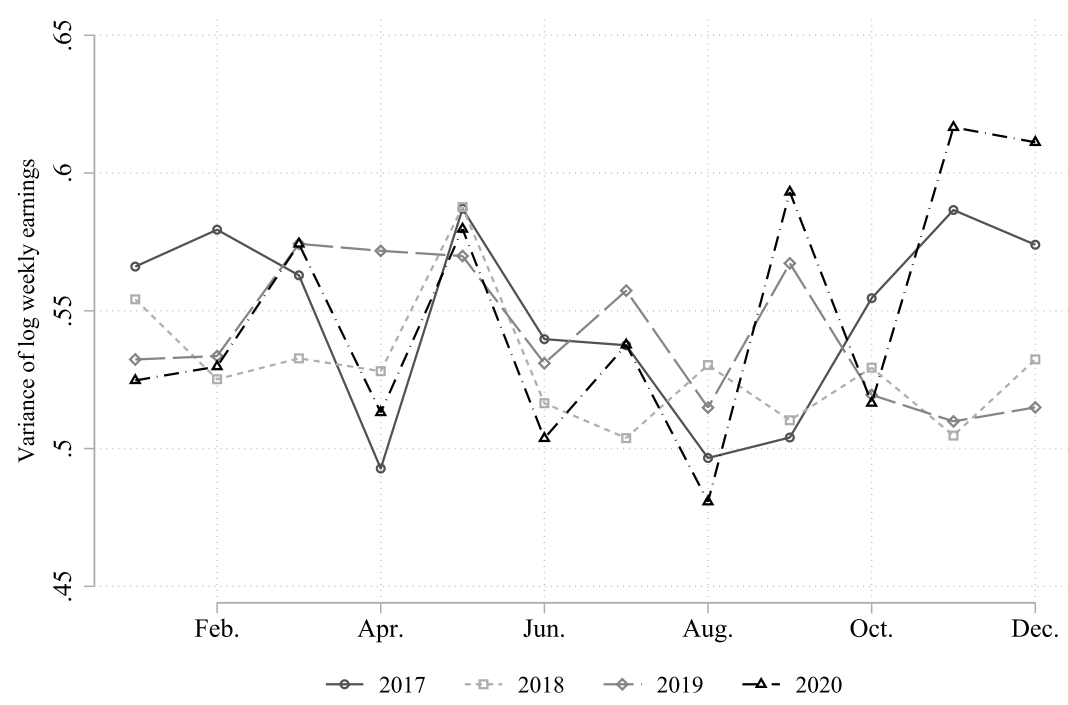

Fig. 6 Variance of log weekly earnings, 2017-2020. Samples are limited to positive earners among those in outgoing rotation group. Earnings weight is applied

Last but not least, we examine changes in inequality of weekly earnings. Figure 6 shows the variance of log weekly earnings across months in 2017-2020. Overall patterns across calendar months did not differ noticeably between 2020 and the previous years. We also cross-checked changes in inequality of equivalized household income (results not shown here), finding that the pattern is similar to that of individual earnings.

\section{Discussion and Conclusion}

\section{Who is "She" in the "She-Cession"?}

Utilizing 2017-2020 CPS monthly data, we investigated variation in the effects of COVID-19 on at-work status across gender, marital status, and parenthood. Table 1 summarizes our findings by the most refined grouping. There are several noteworthy findings. First, the impression that the COVID-19-related recession is a "she-cession" is misleading. There is substantial variation among female groups. Not-currently married male groups were more disadvantaged than married women without school-aged children.

Second, age of children matters. The employment of married women of schoolaged children was more negatively impacted by COVID-19 than that of married fathers even after adjusting for seasonal fluctuation. The negative impact on this group was more pronounced during the school reopening period from September to October. The relatively larger negative impact on married women of school-aged children was associated with their unique occupational and industrial distribution. 
Table 1 Relative (dis)advantage compared to married fathers in proportion at work, setting January 2020 as a reference point

\begin{tabular}{|c|c|c|c|c|c|c|c|c|c|}
\hline \multirow[t]{2}{*}{ Group } & \multicolumn{9}{|c|}{ Month in 2020} \\
\hline & Apr & May & Jun & Jul & Aug & Sep & Oct & Nov & Dec \\
\hline \multicolumn{10}{|c|}{ I. Highly educated $(\operatorname{Ref}=$ Equally educated married fathers with youngest child ages $18+)$} \\
\hline Married father, youngest 6-17 & + & + & $\Delta$ & $\Delta$ & $\Delta$ & $\Delta$ & $\Delta$ & $\Delta$ & $\Delta$ \\
\hline Married father, youngest $0-5$ & + & $\Delta$ & $\Delta$ & $\Delta$ & $\Delta$ & $\Delta$ & $\Delta$ & $\Delta$ & $\Delta$ \\
\hline Married childless men & + & $\Delta$ & $\Delta$ & $\Delta$ & $\Delta$ & $\Delta$ & $\Delta$ & $\Delta$ & $\Delta$ \\
\hline Single men & $\Delta$ & $\Delta$ & $\Delta$ & $\Delta$ & $\Delta$ & $\Delta$ & $\Delta$ & $\Delta$ & $\Delta$ \\
\hline Cohabiting men & + & $\Delta$ & $\Delta$ & $\Delta$ & $\Delta$ & $\Delta$ & $\Delta$ & $\Delta$ & $\Delta$ \\
\hline Sep/Div/Wid men & $\Delta$ & $\Delta$ & $\Delta$ & $\Delta$ & $\triangle$ & $\Delta$ & $\Delta$ & $\Delta$ & $\Delta$ \\
\hline Married mother, youngest $18+$ & $\Delta$ & $\Delta$ & $\Delta$ & $\Delta$ & $\triangle$ & $\Delta$ & $\Delta$ & $\triangle$ & $\Delta$ \\
\hline Married mother, youngest 6-17 & $\triangle$ & $\Delta$ & $\triangle$ & $\Delta$ & $\Delta$ & $\Delta$ & $\Delta$ & $\Delta$ & $\Delta$ \\
\hline Married mother, youngest $0-5$ & + & $\Delta$ & $\Delta$ & $\Delta$ & $\Delta$ & $\Delta$ & $\Delta$ & $\Delta$ & $\Delta$ \\
\hline Married childless women & $\Delta$ & $\Delta$ & $\triangle$ & $\Delta$ & $\Delta$ & $\Delta$ & $\Delta$ & $\Delta$ & $\Delta$ \\
\hline Single mothers & $\Delta$ & $\Delta$ & $\Delta$ & $\Delta$ & $\Delta$ & $\Delta$ & $\Delta$ & $\Delta$ & $\Delta$ \\
\hline Single childless women & + & $\Delta$ & $\Delta$ & $\Delta$ & $\Delta$ & $\Delta$ & $\Delta$ & $\Delta$ & $\Delta$ \\
\hline Cohabiting women & $\Delta$ & $\Delta$ & $\Delta$ & $\Delta$ & $\Delta$ & $\Delta$ & $\Delta$ & $\Delta$ & $\Delta$ \\
\hline Sep/Div/Wid women & $\Delta$ & $\Delta$ & $\Delta$ & $\Delta$ & $\Delta$ & $\Delta$ & $\Delta$ & $\Delta$ & $\Delta$ \\
\hline
\end{tabular}

II. Less educated $(\operatorname{Ref}=$ Equally educated married fathers with youngest child ages $18+)$

\begin{tabular}{llllllllll} 
Married father, youngest 6-17 & $\Delta$ & $\Delta$ & $\Delta$ & $\Delta$ & $\Delta$ & $\Delta$ & $\Delta$ & $\Delta$ & $\Delta$ \\
Married father, youngest 0-5 & - & $\Delta$ & $\Delta$ & - & - & $\Delta$ & $\Delta$ & $\Delta$ & $\Delta$ \\
Married childless men & $\Delta$ & $\Delta$ & - & $\Delta$ & - & - & $\Delta$ & $\Delta$ & $\Delta$ \\
Single men & - & - & $\Delta$ & $\Delta$ & - & $\Delta$ & $\Delta$ & $\Delta$ & $\Delta$ \\
Cohabiting men & - & - & $\Delta$ & $\Delta$ & - & - & $\Delta$ & $\Delta$ & $\Delta$ \\
Sep/Div/Wid men & $\Delta$ & $\Delta$ & $\Delta$ & $\Delta$ & - & - & - & $\Delta$ & $\Delta$ \\
Married mother, youngest 18+ & $\Delta$ & $\Delta$ & $\Delta$ & $\Delta$ & $\Delta$ & $\Delta$ & $\Delta$ & + & $\Delta$ \\
Married mother, youngest 6-17 & $\Delta$ & - & $\Delta$ & $\Delta$ & - & - & - & $\Delta$ & $\Delta$ \\
Married mother, youngest 0-5 & $\Delta$ & $\Delta$ & $\Delta$ & $\Delta$ & $\Delta$ & $\Delta$ & $\Delta$ & $\Delta$ & $\Delta$ \\
Married childless women & $\Delta$ & $\Delta$ & $\Delta$ & $\Delta$ & $\Delta$ & - & $\Delta$ & $\Delta$ & $\Delta$ \\
Single mothers & - & - & - & - & - & - & - & $\Delta$ & - \\
Single childless women & - & - & - & - & - & - & - & - & - \\
Cohabiting women & - & $\Delta$ & - & $\Delta$ & $\Delta$ & $\Delta$ & $\Delta$ & $\Delta$ & $\Delta$ \\
Sep/Div/Wid women & $\Delta$ & $\Delta$ & $\Delta$ & $\Delta$ & $\Delta$ & - & $\Delta$ & $\Delta$ & $\Delta$ \\
\hline
\end{tabular}

Results are based on Fig. 4A. + indicates relative advantage compared to married fathers that is statistically significant at least .05 alpha level and - indicates relative disadvantage. $\triangle$ means statistically nonsignificant

There are more married women working in education sectors, which are sensitive to seasonal fluctuations and school reopenings.

Third, never-married childless women and never-married mothers were the two groups who bore the most negative impacts of COVID-19. For a prolonged period after the initial lockdown, never-married women and mothers were substantially and statistically significantly more disadvantaged than other groups. 
Never-married men were relatively more disadvantaged compared to married fathers as well. However, unlike never-married women and mothers, their disadvantages lasted for a relatively short period right after the lockdown.

Fourth, when we disaggregate the demographic groups further by education, no groups, including never-married women and mothers, experienced a greater relative drop in employment than married fathers when they had a bachelor's degree. Variation across demographic groups was observed only among the lesseducated. The employment rates of all less-educated never-married singlesincluding not-currently married men, never-married childless women, and nevermarried mothers-were more negatively affected by the pandemic for a prolonged period. Differences in occupational and industrial distributions only partially accounted for the larger relative disadvantages for these groups. Among married individuals, less-educated married men without children and less-educated married mothers of school-aged children were also disadvantaged compared to equally educated married fathers.

Fifth, the variation in the negative impact of COVID-19 on labor-market outcomes across demographic groups was primarily in employment. Among those who stayed employed, the differences in changes in work hours and earnings across groups were at most minor.

Some may wonder if the observed variation across marital status and education is a reflection of the racial composition of these groups, as there is a noticeable racial gap in marriage rates (Bloome \& Ang, 2020), and blacks and Hispanics are over-represented among unmarried mothers in our sample. As a robustness check, we reassessed our models by dropping one racial/ethnic minority group at a time (results not shown here), finding that the considerable disadvantage of never-married singles, especially among the less-educated, did not reflect differences in racial composition.

Overall, our results clearly demonstrate that the impacts of the pandemic recession on labor-market outcomes were quite heterogeneous and complex. Contrary to the perception of a she-cession, married women without school-aged children were not worse off compared to married fathers. The unique features of the pandemic recession are found elsewhere. Less-educated never-married women, regardless of motherhood, were distinctively more negatively affected by COVID-19 than other groups. The amplified burden of childcare at the onset of the lockdown and school closings may have taken a heavy toll on the employment of never-married mothers. Their lack of flexibility in adapting to the increased load of childcare may have driven less-educated never-married mothers away from their employment. The pandemic did not only impose unprecedented childcare and educational burdens on parents; it also increased the burden of self-care for all. Many individuals without partners or spouses lacked the luxury of either remote working or shared caregiving responsibilities. Marriage and partnership seem to have provided a buffer in dealing with the pandemic's negative shocks. These results raise new research questions on the role of marriage during the pandemic recession and in the new teleworking culture. 


\section{Within-Family Insurance and the Added Caregiver Effect}

In the past, family has tended to offer a buffer against economic shocks such as recessions, a phenomenon called within-family insurance (Alon et al., 2020b; Sahin et al., 2010). Existing literature on within-family insurance centers on the "added worker effect," where the decrease or loss in one spouse's earnings leads to an increase in the probability of working or the absolute number of hours worked by the other spouse (Stephens, 2002; Juhn \& Potter, 2007). The assumption is that to maximize family utility, one spouse's displacement promotes the other spouse's labor-market behavior to compensate for the lost income. While we see both the support for (Sahin et al., 2010) and limitations (Landivar et al., 2020) of such an explanation, within-family insurance in a pandemic recession may drastically differ.

Reduction in employment is a common trait of all recessions. The heightened burden of childcare, children's education, and self-care, as well as the introduction of physical and social distancing, were the peculiarities of the pandemic recession. Sociological studies on the gendered impact of the pandemic have focused on married couples because school-closing and stay-at-home orders increased the childcare burden for couples (Collins et al., 2021; Petts et al., 2021; Carlson et al., 2020; Calarco et al., 2020; Landivar et al., 2020). However, there is an additional form of care that was affected by the pandemic: self-care. Previous studies showed that the social support provided by a spouse or partner can work as a stress absorber (Carlson \& Kail, 2018; Cohen \& Wills, 1985). Partnered couples offer both physical and emotional care services to each other. The reduction in, or complete lack of, social activities as a result of physical and social distancing may have jeopardized emotional self-care, especially for those who rely on social networks outside families.

Our results indicate that marriage and partnership may have still worked as within-family insurance during the pandemic recession. The main mechanism for within-family insurance during the pandemic, however, would not be the "added worker effect." Unlike in previous recessions, unemployment benefits were extended by the federal Coronavirus Aid, Relief, and Economic Security Act (CARES) in 2020, which increased benefits, extended the benefit period, and included previously uncovered workers. As a result, the incentive of providing an added worker became lower.

Instead, the "added caregiver effect" seems to have been the main mechanism of within-family insurance during the pandemic recession. Here, the responsibilities of caregiving include both childcare and self-care. We do not argue that marriage necessarily reduces the burden of childcare for women during the recession. Instead, we point out that a partner in the same household can at least offer caregiving service when necessary, providing a flexibility never-married singles cannot enjoy (Petts et al., 2021). The value of such flexibility was particularly high during the pandemic because the requirement of physical distancing made it hard to find a reliable emergency caregiver outside the family. If teleworking remains common after the pandemic recession has ended, we argue that the added caregiver effect may become a permanent feature of labor markets to some extent. With teleworking, the frequency at which parents work at home while their children are present will rise. If childcare becomes less accessible, the role of the 
added caregiver will be enhanced. Thus, as teleworking becomes a part of the New Normal, reliable and easily accessible childcare services will become even more important than before, especially for single mothers.

The fact that the employment gap between married mothers and never-married mothers was larger among those without bachelor's degrees suggests that the shock-absorbing effect of an added caregiver is especially larger among the lesseducated. Given that other resources are more limited for less-educated individuals than for those with college degrees, the benefits of within-family insurance seem to have been more valuable for the less-educated. Previous research suggests that the social support provided by a spouse is more beneficial to the wellbeing of lower-SES individuals because, relative to higher-SES individuals, they tend to lack other sources of social support outside of marriage (Carlson \& Kail, 2018). The radical limitations on social interaction resulting from lockdowns and distancing guidelines may have had an especially harmful effect, then, on unpartnered lower-SES individuals, because they lacked social and emotional support relative to partnered low-SES individuals or higher-SES individuals regardless of marital or partnership status. The pandemic may have been especially socially isolating for unpartnered low-SES individuals. For low-SES individuals without children, in particular, the added caregiver effect may be understood as the insurance provided by the presence of a partner or spouse who can perform not just household care work such as cooking and cleaning but also emotional and social care work for their partner during times of widespread stress or social isolation, such as a pandemic emergency. We propose that such an effect contributed to the labor-market disadvantages we observe among less-educated never-married women during the pandemic recession in particular, regardless of parenthood status.

This study investigated variations in the impact of COVID-19 on at-work status across demographic groups, contributing to the literature by exposing much more complicated effects of the pandemic across demographic groups and suggesting a new theoretical explanation of within-family insurance. This study is not without limitations. First, the analyses presented here are by no means causal. While we find it crucial to account for seasonal fluctuations in assessing disadvantages across our groups of interest, our goal is to estimate relative (dis)advantage more precisely rather than to explore the causal mechanisms of the pandemic recession. Second, our estimates are of changes in at-work status among the working-age population, not within-individual change due to the pandemic. Although the CPS's outgoing rotation sample design does make it possible to create mini-panel data, the utility of such a design is limited in this case because a given individual is followed only 4 months in a given year. Third, we are unable to test alternative explanations, such as the possibility that never-married singles were more concentrated in jobs that were vulnerable to the pandemic recession in a way that could not be fully accounted for by the control of occupation, industry, and part-time employment. Fourth, although we suggest a new theoretical argument about within-family insurance, this study does not empirically examine how family dynamics affected gendered labor supply during the pandemic recession. Whether marriage and partnership will continue to play a more prominent role in the labor market in the era of teleworking, and, if so, 
what policies can be developed to make a more supportive community for nevermarried singles are topics for future research.

\section{Appendix}

See Table 2 and Figs. 7 and 8

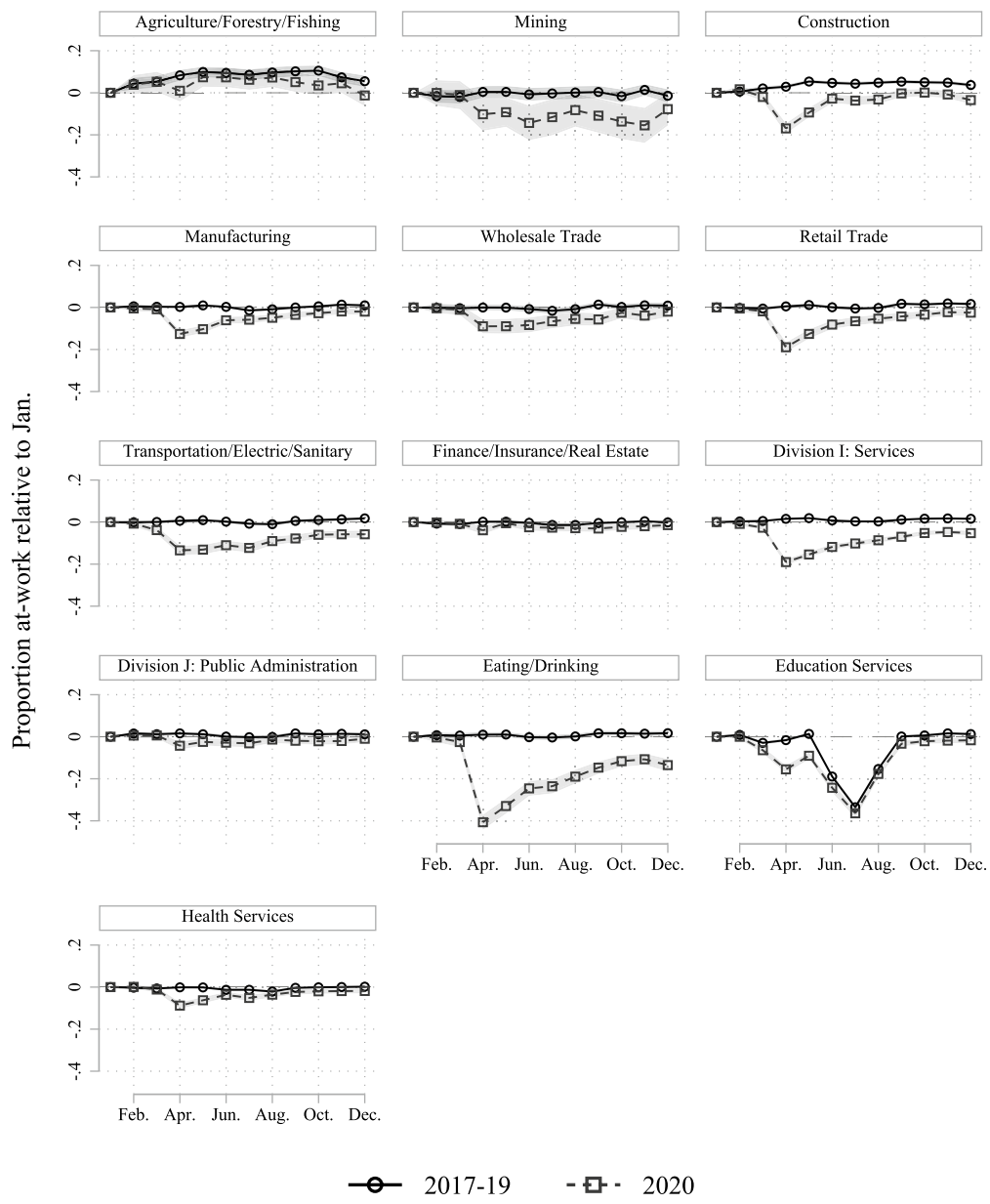

Fig. 7 Proportion at work vs. January by industry, 2017-2020. Control variables include gender, age, age squared, levels of education, race, citizenship status, state fixed effects, metro status, marital status, number of children in the household and survey year for 2017-2019. Vertical bars indicate 95\% confidence intervals based on robust standard errors 

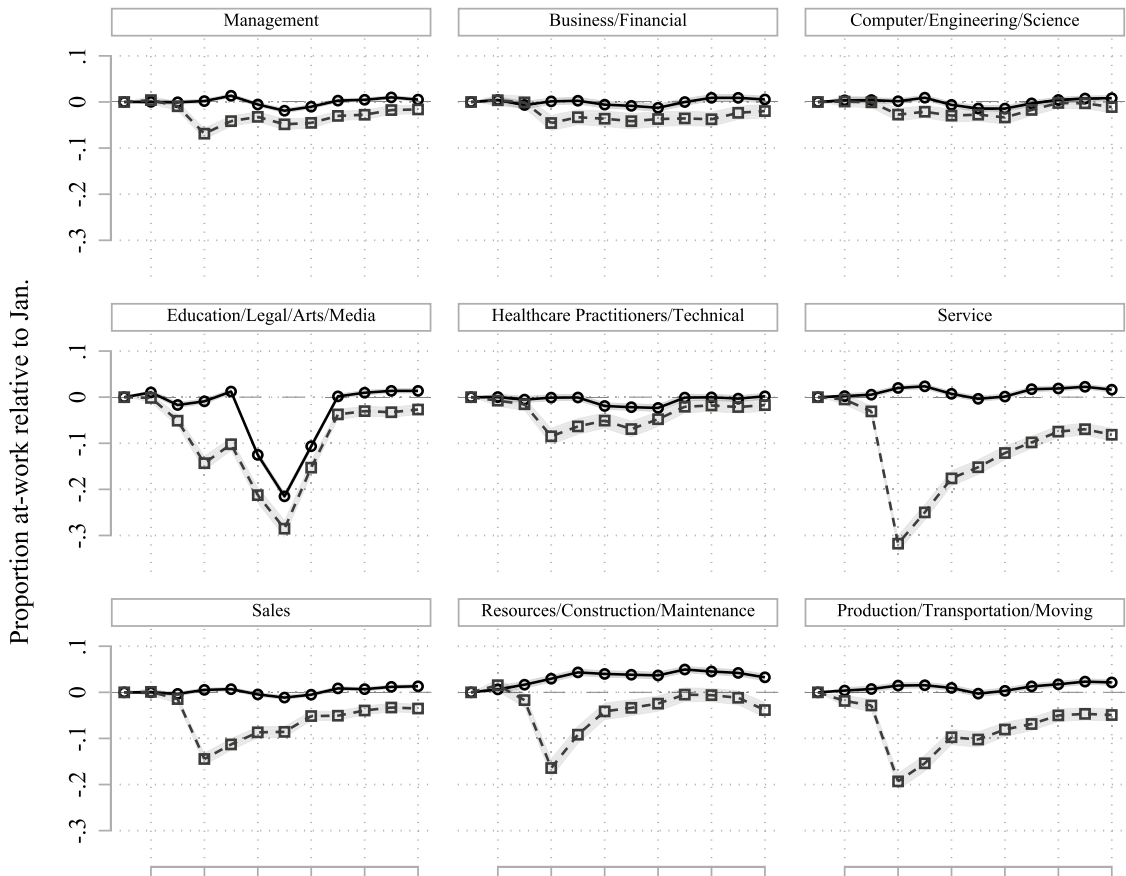

Feb. Apr. Jun. Aug. Oct. Dec. Feb. Apr. Jun. Aug. Oct. Dec. Feb. Apr. Jun. Aug. Oct. Dec.

- 2017-19 - - - 2020

Fig. 8 Proportion at work vs. January by occupation, 2017-2020. Control variables include gender, age, age squared, levels of education, race, citizenship status, state fixed effects, metro status, marital status, number of children in the household and survey year for 2017-2019. Vertical bars indicate $95 \%$ confidence intervals based on robust standard errors 


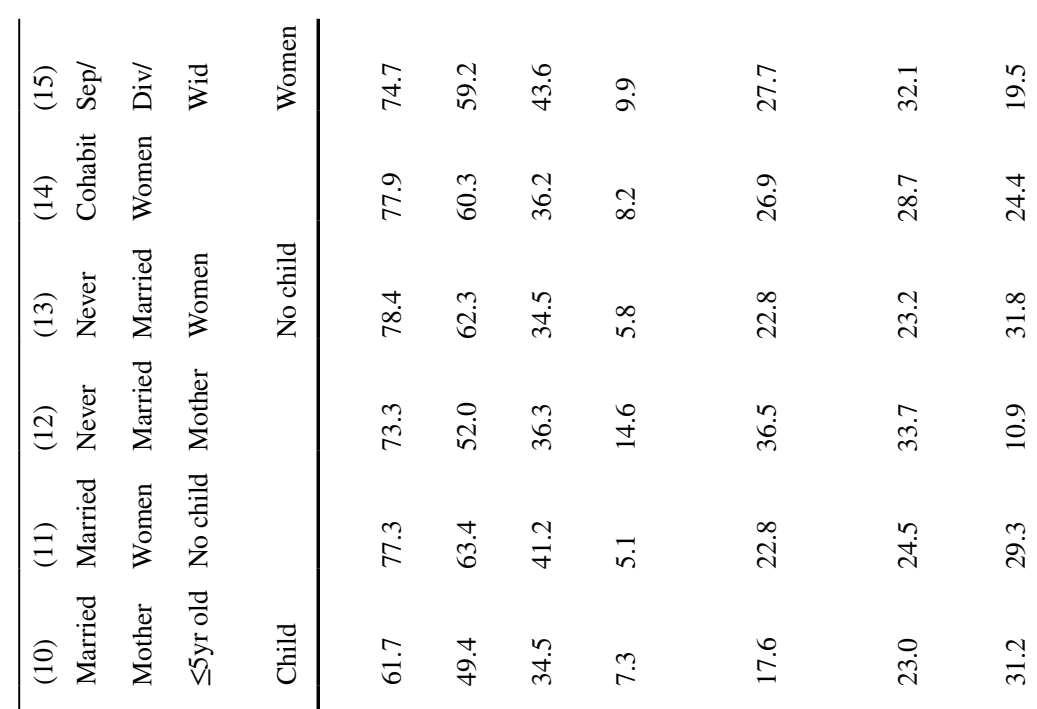

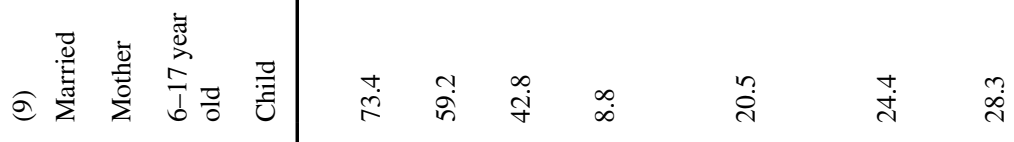

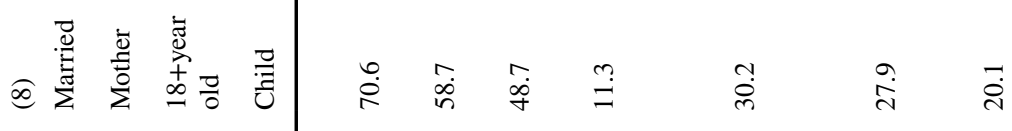

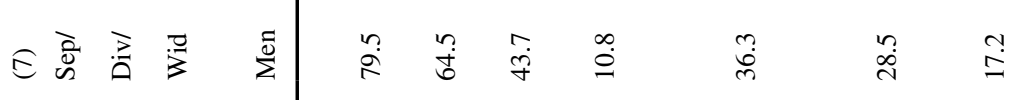

ف

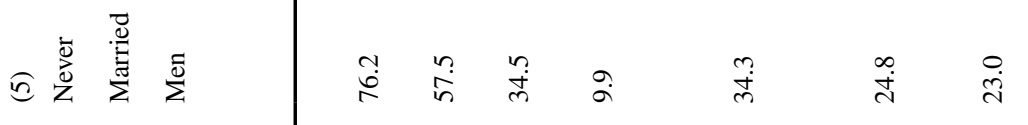

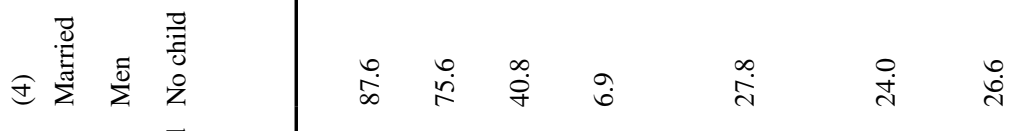

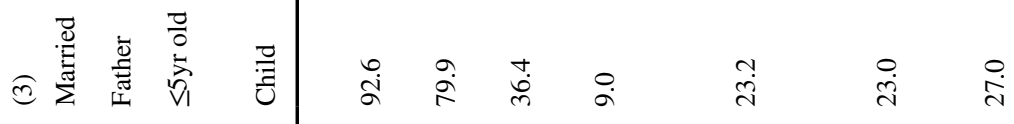

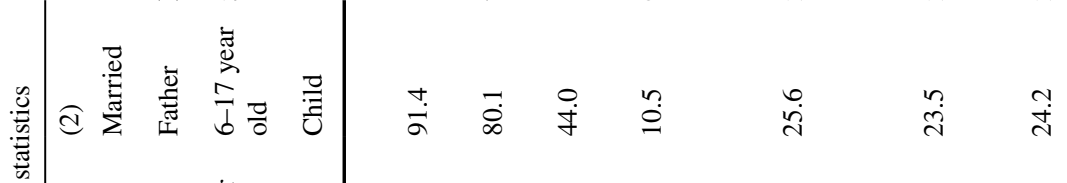

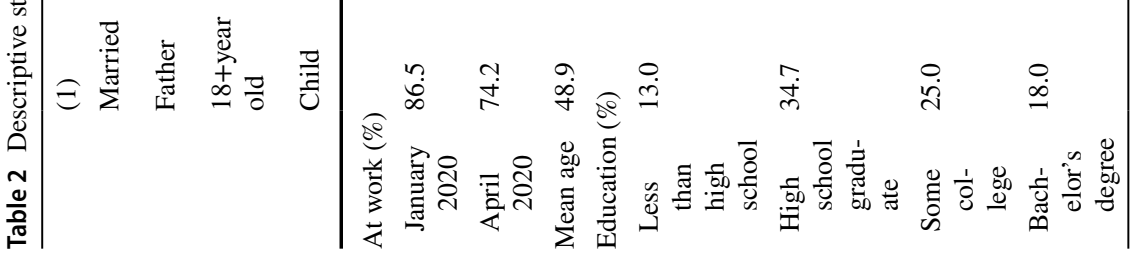




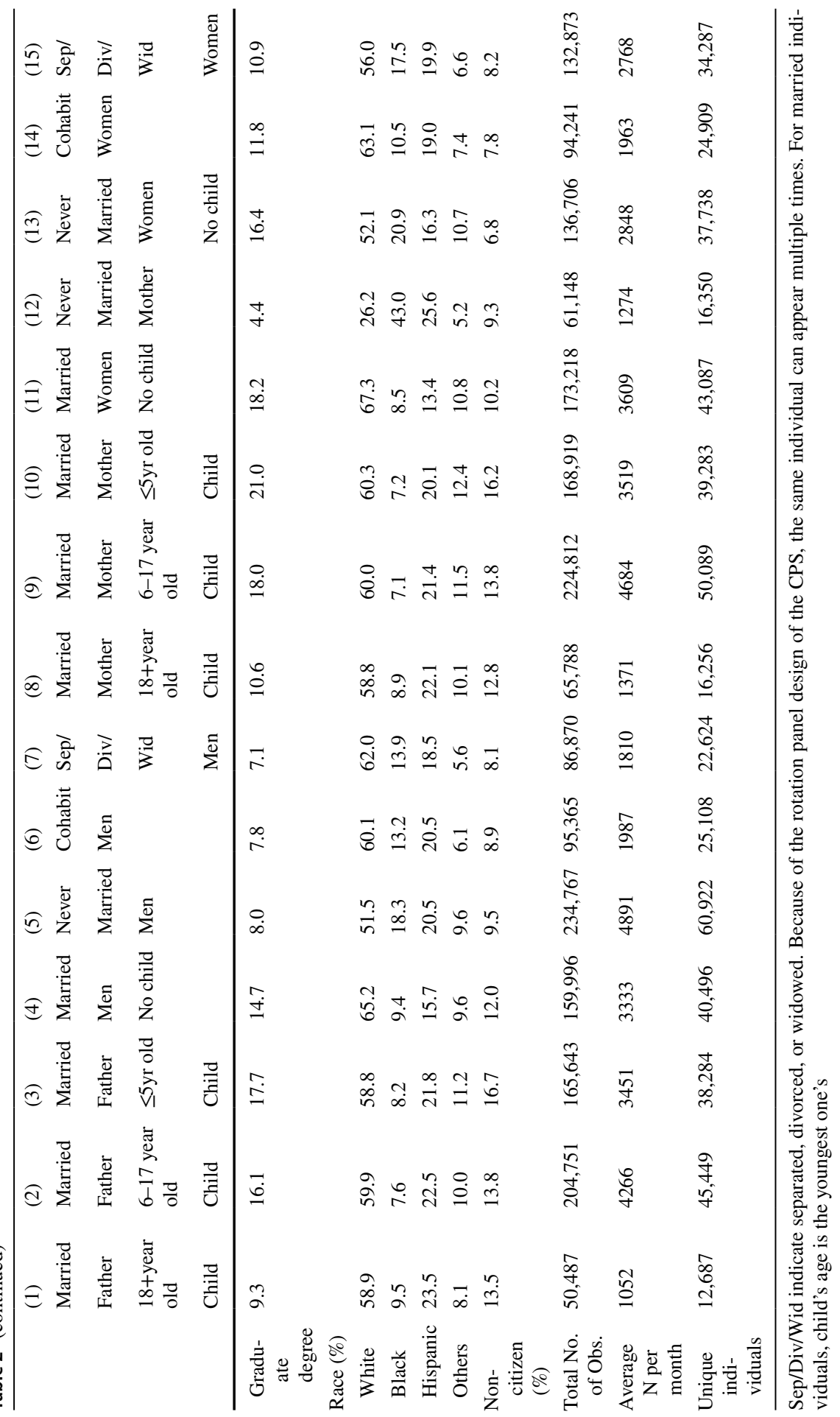


Funding The authors have no relevant financial or non-financial interests to disclose.

Data Availability All datasets used for analyses are available from https://cps.ipums.org/cps/

\section{Declarations}

Conflict of interest The authors have no conflicts of interest to declare that are relevant to the content of this article.

\section{References}

Adams-Prassl, A., Boneva, T., Golin, M., \& Rauh, C. (2020). Inequality in the impact of the Coronavirus shock: Evidence from real time surveys. IZA Discussion Paper, 13183.

Alon, T., Doepke, M., Olmstead-Rumsey, J., \& Tertilt, M. (2020a). The impact of COVID-19 on gender equality. NBER Working Paper 26947. https://doi.org/10.3386/w26947.

Alon, T., Doepke, M., Olmstead-Rumsey, J., \& Tertilt, M. (2020b). This time it's different: The role of women's employment in a pandemic recession. NBER Working Paper 27660, https://doi.org/10. 3386/w27660

Averett, K. H. (2021). A feminist public sociology of the pandemic: Interviewing about a crisis, during a crisis. Gender, Work\&amp; Organization, 28(S2), 321-329. https://doi.org/10.1111/gwao.12616

Barkowski, S., McLaughlin, J., \& Dai, Y. (2020). Young children and parents' labor supply during COVID-19, SSRN. July 27. https://doi.org/10.2139/ssrn.3930776

Barsky, R. B., \& Miron, J. A. (1989). The seasonal cycle and the business cycle. Journal of Political Economy, 97(3), 503-534. https://doi.org/10.1086/261614.

Berik, G., \& Kongar, E. (2013). Time allocation of married mothers and fathers in hard times: The 200709 US recession. Feminist Economics, 19(3), 208-237. https://doi.org/10.1080/13545701.2013. 798425.

Berthelon, M., Kruger, D., \& Oyarzún, M. (2015). The effects of longer school days on mothers' labor force participation. IZA Discussion Paper 9212.

Birinci, S. (2019). Spousal labor supply response to job displacement and implications for optimal transfers. Working Paper 2019-020B, Federal Reserve Bank of St. Louis. https://doi.org/10.20955/wp. 2019.020

Blair-Loy, M. (2003). Competing devotions: Career and family among women executives. Harvard University Press.

Bloome, D., \& Ang, S. (2020). Marriage and union formation in the United States: Recent trends across racial groups and economic backgrounds. Demography, 57(5), 1753-1786. https://doi.org/10.1007/ s13524-020-00910-7

Blundell, R., Pistaferri, L., \& Saporta-Eksten, I. (2016). Consumption inequality and family labor supply. American Economic Review, 106(2), 387-435. https://doi.org/10.1257/aer.20121549

Borbely, J. M. (2011). Characteristics of displaced workers 2007-2009: A visual essay. Monthly Labor Review, 134, 3-15.

Cajner, T., Crane, L. D., Decker, R. A., Grigsby, J., Hamins-Puertolas, A., Hurst, E., Kurz, C., \& Yildirmaz, A. (2020). The U.S. labor market during the beginning of the pandemic recession. NBER Working Paper 27159. https://doi.org/10.1017/CBO9781107415324.004

Calarco, J. M., Meanwell, E., Anderson, E., \& Knopf, A. (2020). "My husband thinks I'm crazy": COVID-19-related conflict in couples with young children, SocArXiv. October 9. https://doi.org/10. 31235/osf.io/cpkj6

Capizzano, J., Adelman, S., \& Stagner, M. (2002). What happens when the school year is over? The use and costs of child care for school-age children during the summer. Urban Institute Occasional Paper 58. Retrieved May 1, 2021 from http://www.urban.org/url.cfm?ID=310497.

Carlson, D. L., \& Kail, B. L. (2018). Socioeconomic variation in the association of marriage with depressive symptoms. Social Science Research, 71, 85-97. https://doi.org/10.1016/j.ssresearch.2017.12. 008 
Carlson, D. L., Petts, R., Pepin, J. (2020). Changes in parents' domestic labor during the COVID-19 pandemic, SocArXiv. May 6. https://doi.org/10.31235/osf.io/jy8fn

Cohen, S., \& Wills, T. A. (1985). Stress, social support, and the buffering hypothesis. Psychological Bulletin, 98(2), 310-357. https://doi.org/10.1037/0033-2909.98.2.310

Collins, C., Landivar, L. C., Ruppanner, L., \& Scarborough, W. J. (2021). COVID-19 and the gender gap in work hours. Gender, Work\&amp; Organization, 28(S1), 101-112. https://doi.org/10.1111/gwao. 12506

Correll, S. J., Benard, S., \& Paik, I. (2007). Getting a job: Is there a motherhood penalty? American Journal of Sociology, 112(5), 1297-1339. https://doi.org/10.1086/511799

Dias, F. A., Chance, J., \& Buchanan, A. (2020). The motherhood penalty and the fatherhood premium in employment during COVID-19: Evidence from the United States. Research in Social Stratification and Mobility, 69, 100542. https://doi.org/10.1016/j.rssm.2020.100542

Dunne, T., \& Fee, K. (2010). The labor market for men and women. Economic Trends. Retrieved May 1, 2021 from https://www.clevelandfed.org/newsroom-and-events/publications/economic-trends/econo mic-trends-archives/2010-economic-trends/et-20100719-the-labor-market-for-men-and-women.

England, P. (2010). The gender revolution: Uneven and stalled. Gender \& Society, 24(2), 149-166. https://doi.org/10.1177/0891243210361475

Flood, S., King, M., Rodgers, R., Ruggles, S., \& Warren, J. R. (2020). Integrated Public Use Microdata Series, Current Population Survey: Version 8.0 [dataset]. IPUMS.

Fornaro, C. J., Struloeff, K., Sterin, K., \& Flowers, A. M., III. (2021). Uncharted territory: Educational leaders managing out-of-school programs during a global pandemic. International Studies in Educational Administration, 49(1), 101-108.

Fothergill, A. (1998). The neglect of gender in disaster work: An overview of the literature. In E. Enarson \& B. Morrow (Eds.), The Gendered Terrain of Disaster: Through Women's Eyes (pp. 11-25). Praeger Publishers.

Ganong, P., Noel, P., \& Vavra, J. (2020). US unemployment insurance replacement rates during the pandemic. Journal of Public Economics, 191, 104273. https://doi.org/10.1016/j.jpubeco.2020. 104273

Geremew, M., \& Gourio, F. (2018). Seasonal and business cycles of US employment. Economic Perspectives, 42(3), 1-28. https://doi.org/10.21033/ep-2018-3

Goldin, C., \& Mitchell, J. (2017). The new life cycle of women's employment: Disappearing humps, sagging middles, expanding tops. Journal of Economic Perspectives, 31(1), 161-182. https://doi. org/10.1257/jep.31.1.161

Goodman, C. J., \& Mance, S. M. (2011). Employment loss and the 2007-09 recession: An overview. Monthly Labor Review, 134(4), 3-12.

Goodman, W., Antczak, S., \& Freeman, L. (1993). Women and jobs in recessions: 1969-92. Monthly Labor Review, 116(7), 26-35.

Graves, J. (2013). School calendars, child care availability and maternal employment. Journal of Urban Economics, 78, 57-70. https://doi.org/10.1016/j.jue.2013.07.004

Hartmann, H., Shaw, E., \& O'Connor, R. (2014). Women and men in the recovery: Where the jobs are. Briefing Paper C426, Institute for Women's Policy Research.

Hout, M., Levanon, A., \& Cumberworth, E. (2011). Job loss and unemployment. In D. B. Grusky, B. Western, \& C. Wimer (Eds.), The great recession (pp. 59-81). Russell Sage Foundation.

Hoynes, H., Miller, D. L., \& Schaller, J. (2012). Who suffers during recessions? Journal of Economic Perspectives, 26(3), 27-48. https://doi.org/10.1257/jep.26.3.27

Jelliffe, E., Pangburn, P., Pichler, S., \& Ziebarth, N. R. (2021). Awareness and use of (emergency) sick leave: US employees' unaddressed sick leave needs in a global pandemic. Proceedings of the National Academy of Sciences of the United States of America, 118(2), e2107670118. https:// doi.org/10.1073/pnas.2107670118

Juhn, C., \& Potter, S. (2007). Is there still an added-worker effect? Federal Reserve Bank of New York Staff Reports. https://doi.org/10.2139/ssrn.1072022.

Kelliher, C. (1989). Flexibility in employment: Developments in the hospitality industry. International Journal of Hospitality Management, 8(2), 157-166. https://doi.org/10.1016/02784319(89)90075-3

Kim, A. T., Kim, C., Tuttle, S. E., \& Zhang, Y. (2021). COVID-19 and the decline in Asian American employment. Research in Social Stratification and Mobility, 71, 100563. https://doi.org/10.1016/j. rssm.2020.100563 
Laird, J. (2017). Public sector employment inequality in the United States and the Great Recession. Demography, 54(1), 391-411. https://doi.org/10.1007/s13524-016-0532-4

Landivar, L. C., Ruppanner, L., Scarborough, W. J., \& Collins, C. (2020). Early signs indicate that COVID-19 is exacerbating gender inequality in the labor force. Socius: Sociological Research for a Dynamic World, 6, 1-3. https://doi.org/10.1177/2378023120947997

Laughlin, L. (2010). Who's minding the kids? Child care arrangements: Spring 2005 and summer 2006. Current Population Reports August:P70-121.

Lundberg, S. (1985). The added worker effect. Journal of Labor Economics, 3(1), 11-37. https://doi.org/ $10.1086 / 298069$

Lyttelton, T., Zang, E., \& Musick, K. (2020). Gender differences in telecommuting and implications for inequality at home and work, SocArXiv. July 9. https://doi.org/10.31235/osf.io/tdf8c

Miron, J. A. (1996). The Economics of Seasonal Cycles. Cambridge, MA: MIT Press.

Moen, P., Pedtke, J. H., \& Flood, S. (2020). Disparate disruptions: Intersectional COVID-19 employment effects by age, gender, education, and race/ethnicity. Work, Aging and Retirement, 6(4), 207-228. https://doi.org/10.1093/workar/waaa013

Montenovo, L., Jiang, X., Rojas, F. L., Schmutte, I. M., Simon, K. I., Weinberg, B. A., \& Wing, C. (2020). Determinants of disparities in Covid-19 job losses. NBER Working Paper 27132. https:// doi.org/10.3386/w27132

Morrow, B. H. (1999). Identifying and mapping community vulnerability. Disasters, 23, 1-18. https://doi. org/10.1111/1467-7717.00102

Morrow, B. H., \& Enarson, E. (1996). Hurricane Andrew through women's eyes. International Journal of Mass Emergencies and Disasters, 14(1), 5-22.

Papanikolaou, D., \& Schmidt, L. D. W. (2020). Working remotely and the supply-side impact of Covid19. NBER Working Paper 27330. https://doi.org/10.3386/w27330

Peek, L., \& Fothergill, A. (2008). Displacement, gender, and the challenges of parenting after Hurricane Katrina. NWSA Journal, 20(3), 69-106.

Petts, R. J., Carlson, D. L., \& Pepin, J. R. (2021). A gendered pandemic: Childcare, homeschooling, and parents' employment during covid-19. Gender, Work\&amp; Organization, 28, 515-534. https://doi. org/10.1111/gwao.12614

Pruitt, S., \& Turner, N. (2020). Earnings risk in the household: Evidence from millions of US tax returns. American Economic Review: Insights, 2(2), 237-254. https://doi.org/10.1257/aeri.20190096

Raley, S. B., Mattingly, M. J., \& Bianchi, S. M. (2006). How dual are dual-income couples? Documenting change from 1970 to 2001. Journal of Marriage and Family, 68(1), 11-28. https://doi.org/10. 1111/j.1741-3737.2006.00230.x

Redbird, B., \& Grusky, D. B. (2016). Distributional effects of the Great Recession: Where has all the sociology gone? Annual Review of Sociology, 42(1), 185-215. https://doi.org/10.1146/annur ev-soc-073014-112149

Ruppanner, L., Moller, S., \& Sayer, L. (2019). Expensive childcare and short school days = lower maternal employment and more time in childcare? Evidence from the American Time Use Survey. Socius: Sociological Research for a Dynamic World, 5, 1-14. https://doi.org/10.1177/2378023119860277.

Sahin, A., Song, J., \& Hobijn, B. (2010). The unemployment gender gap during the 2007 recession. Current Issues in Economics and Finance, 16(2), 1-7. https://doi.org/10.2139/ssrn.1582525

Sarkisian, N., \& Gerstel, N. (2008). Till marriage do us part: Adult children's relationships with their parents. Journal of Marriage and Family, 70(2), 360-376. https://doi.org/10.1111/j.1741-3737.2008. 00487.x

Schwartz, C. R., \& Mare, R. D. (2005). Trends in educational assortative marriage from 1940 to 2003. Demography, 42(4), 621-646. https://doi.org/10.1353/dem.2005.0036

Sevilla, A., \& Smith, S. (2021). Baby steps: The gender division of childcare during the COVID-19 pandemic. Oxford Review of Economic Policy, 36(S1), S169-S186. https://doi.org/10.1093/oxrep/graa0 27

Stephens, M. (2002). Worker displacement and the added worker effect. Journal of Labor Economics, 20(3), 504-537. https://doi.org/10.1086/339615

Stone, P. (2007). Opting Out?: Why Women Really Quit Careers and Head Home. University of California Press.

Tedeschi, E. (2020). COVID-19, school closures, and US parental labor outcomes, Working Paper. https://rebrand.ly/evt_parents 
US Bureau of Labor Statistics (2020). Frequently asked questions: The impact of the Coronavirus (COVID-19) pandemic on the employment situation for april 2020. Retrieved May 1, 2021 from https://www.bls.gov/cps/employment-situation-covid19-faq-april-2020.pdf.

US Department of Labor (2017). Employment and earnings in select occupations. Retrieved May 1, 2021 from https://www.dol.gov/agencies/wb/data/employment-earnings-occupations.

Vigdor, J. (2008). The economic aftermath of Hurricane Katrina. Journal of Economic Perspectives, 22(4), 135-154. https://doi.org/10.1257/jep.22.4.135

Waite, L. J. (1995). Does marriage matter? Demography, 32(4), 483-507. https://doi.org/10.2307/20616 70

Williams, K., Frech, A., \& Carlson, D. L. (2010). Marital status and mental health. In T. L. Scheid \& T. N. Brown (Eds.), A handbook for the study of mental health: Social contexts, theories, and systems (2nd ed., pp. 306-320). Cambridge University Press.

Willinger, B., \& Knight, J. (2012). Setting the stage for disaster: Women in New Orleans before and after Katrina. In E. David \& E. Enarson (Eds.), The women of katrina: How gender, race, and class matter in an American disaster (pp. 55-75). Vanderbilt University Press.

Wing, C., Simon, K., \& Bello-Gomez, R. A. (2018). Designing difference in difference studies: Best practices for public health policy research. Annual Review of Public Health, 39(1), 453-469. https:// doi.org/10.1146/annurev-publhealth-040617-013507.

Publisher's Note Springer Nature remains neutral with regard to jurisdictional claims in published maps and institutional affiliations. 